\title{
$\begin{array}{lllllllllllll}A & R & T & \text { I } & C & \mathrm{~L} & \mathrm{E} & \mathrm{S}\end{array}$
}

\section{Scholarly Impact Revisited}

\author{
by Herman Aguinis, Isabel Suárez-González, Gustavo Lannelongue, and Harry Joo
}

\section{Executive Overview}

Scholarly impact is one of the strongest currencies in the Academy and has traditionally been equated with number of citations-be it for individuals, articles, departments, universities, journals, or entire fields. Adopting an alternative definition and measure, we use number of pages as indexed by Google to assess scholarly impact on stakeholders outside the Academy. Based on a sample including 384 of the 550 most highly cited management scholars in the past three decades, results show that scholarly impact is a multidimensional construct and that the impact of scholarly research on internal stakeholders (i.e., other members of the Academy) cannot be equated with impact on external stakeholders (i.e., those outside the Academy). We illustrate these results with tables showing important changes in the rank ordering of individuals based on whether we operationalize impact considering internal stakeholders (i.e., number of citations) or external stakeholders (i.e., number of non-.edu Web pages). Also, we provide tables listing the most influential scholars inside the Academy who also have an important impact outside the Academy. We discuss implications for empirical research, theory development, and practice regarding the meaning and measurement of scholarly impact.

Each August, we come to talk to each other [at the Academy of Management's annual meetings]; during the rest of the year we read each other's papers in our journals and write our own papers so that we may, in turn, have an audience the following August: an incestuous, closed loop.

Donald C. Hambrick, former Academy of Management president (1994, p. 13)

Some publishing may have become an end in itself. Including the impact of research in the social, economic, and cultural spheres beyond academia is an important corrective to this displacement of goals.

Andrew M. Pettigrew, former British Academy of Management president (2011, p. 348)
W ho are the scholars with the greatest impact in the field of management? Which management departments around the world have the greatest impact based on the aggregated research output of their members? What is the relative impact of individual articles, as well as entire journals, in the field of management? Management scholars are very interested in providing answers to these questions because performance management systems in universities (Aguinis, 2013) and the allocation of resources and rewards to individuals and also departments are determined, at least in part, by the impact of their scholarly work (Gomez-Mejia \& Balkin, 1992; Higher Education Funding Council of England

\footnotetext{
* Herman Aguinis (haguinis@indiana.edu) is the Dean's Research Professor, a Professor of Organizational Behavior and Human Resources, and the Founding Director of the Institute for Global Organizational Effectiveness in the Kelley School of Business, Indiana University.

Isabel Suárez-González (isuarez@usal.es) is a Professor of Management at the Universidad de Salamanca, Salamanca, Spain.

Gustavo Lannelongue (lannelongue@usal.es) is an Assistant Professor of Management at the Universidad de Salamanca, Salamanca, Spain.

Harry Joo (youjoo@indiana.edu) is a doctoral student in Organizational Behavior and Human Resource Management in the Kelley School of Business, Indiana University
} 
[HEFCE], 2011). For example, the Academy of Management Review bestows its best-article-of-thedecade award to the article with the greatest relative impact (Crossan, Maurer, \& White, 2011), and many universities classify journals in terms of their relative impact (Blackburn \& Mitchell, 1981; van Fleet, McWilliams, \& Siegel, 2000).

Because of the importance of the topic, numerous articles have been published in the past few years addressing the impact of our scholarly work. For example, Podsakoff, MacKenzie, Podsakoff, and Bachrach (2008) produced a ranking of researchers based on their relative impact. Judge, Colbert, Cable, and Rynes (2007) analyzed the factors that predict an article's impact. Partington and Jenkins (2007) provided an inductively based framework for understanding why certain articles have more impact than others. Leung (2007) provided an incisive analysis of scholarly impact from an international — and particularly East Asianperspective. Aguinis, Dalton, Bosco, Pierce, and Dalton (2011) assessed whether meta-analyses that focus on theory building have more impact than meta-analyses that focus on theory testing. And Molina-Azorin (2012) examined whether certain methodological approaches have more impact than others. In addition, journal editors continually monitor and report the impact of their journals (e.g., Colquitt, 2011; Cortina, 2011). Evidently, impact is one of the strongest currencies in the Academy.

On the surface, it would seem that the voluminous body of work on the impact of our research is quite diverse and heterogeneous. Some studies have produced rankings of scholars (e.g., Podsakoff et al., 2008). Others have investigated factors likely to affect the impact of individual articles (e.g., Aguinis et al., 2011; Judge et al., 2007). Some researchers have focused on the individual level of analysis (i.e., individual article or individual researcher), whereas others have addressed the department, university, or even field level of analysis (e.g., Certo, Sirmon, \& Brymer, 2010). For example, Lockett and McWilliams (2005) examined the relative impact of various fields on one another and concluded that the field of management, as a whole, runs a significant trade deficit with economics, psychology, and sociology. Also focusing on the relative impact of various fields, Bedeian (2005) argued that it is actually healthy for management to run at a deficit, and the fact that economics does not import as many citations from other fields "may account for what some allege is the parochial nature of the economics literature (reflected in a low level of interdisciplinary knowledge building) as well as an insular pattern of auto-erotic self-referencing (reflected in a high level of intradisciplinary citations)" ( $\mathrm{p}$. 154). Finally, some studies on scholarly impact have used quantitative methods (e.g., Podsakoff et al., 2008), whereas others have adopted a qualitative approach (e.g., Leung, 2007).

Yet despite the seeming heterogeneity of this research, this entire body of work has one important defining feature in common: the definition of impact. These and many other articles have defined impact using the same conceptual and operational definition: number of citations. More precisely, scholarly impact is consistently and uniformly assessed by counting the number of times a particular article, articles in a particular journal, an individual's entire body of work, the body of work of the faculty in a department or university, or the body of work produced by an entire field of study has been cited in scholarly publications. In other words, all of these measures of impact rely on whether other academics cite the article(s) in question in their own scholarly work. Paraphrasing Hambrick's quote included at the beginning of our article, the way we currently assess the impact of our scholarly work seems to be based on an incestuous, closed loop.

Many have expressed concern about a sciencepractice divide in the field of management (e.g., Aguinis, Werner, Abbott, Angert, Park, \& Kohlhausen, 2010; Bansal, Bertels, Ewart, MacConnachie, \& O'Brien, 2012). Specifically, there is concern that the research produced by management scholars does not reach beyond the Academy and may not have substantive impact on stakeholders outside the field, including management and business students, managers, organizations, and society in general (Cascio \& Aguinis, 2008; Rynes, Giluk, \& Brown, 2007). So could it be that researchers who are ranked highly in terms of their impact on other academics, as assessed by 
citations, do not enjoy a similarly high degree of impact on stakeholders outside the Academy?

To answer this question we need to find a way to assess the impact of our scholarly work beyond the Academy, thus addressing Hambrick's call to break out of the closed loop. We do so by using a novel approach to assessing impact: Instead of using number of citations we use number of pages on the Web, as indexed by Google, thus assessing impact outside the Academy at a much broader societal level. The number of citations, as used in past research, and the number of Web pages as indexed by Google, as we use in our study, are similar in that both are general measures of impact. Both are based on a simple count, easy to understand intuitively, and unidimensional. The big difference, however, is that number of citations refers to the impact on a single stakeholder audience: academics-those writing academic publications. In contrast, the number of pages on the Web captures the impact on stakeholders inside and outside the Academy - not only academics but also the media, public and private firms, governments, and nonprofit organizations, among others.

Considering additional similarities between these two measures of impact, the number of citations is a general and broad measure and does not provide information regarding why a source has been cited. It may be that an article is cited as exemplary research or as an example of the opposite- a poorly designed study. It could be that an article is cited in passing in support of the importance and legitimacy of a particular research topic. Or, in contrast, an article may be analyzed and discussed in detail to generate important follow-up questions. In other words, the number of citations is a general measure that is not informative about the type of impact or reason for such impact (Kacmar \& Whitfield, 2000).

Similarly, the number of pages indexed by Google is a general measure of impact that does not include information about the type of impact or reason for the impact (Barjak, Li, \& Thelwall, 2007). For example, a researcher may be mentioned on the Web because her work has been received positively or negatively by the media. Or a researcher may be mentioned because he has participated as an expert witness in a high-profile U.S. Supreme Court case, in an online executive education program, or in a consulting project. Or it could be that a researcher has an important online presence because he has given an interview to a newspaper, or a blogger has decided to write about a popular-press book he has written. Just like number of citations, number of pages on the Web is a measure of impact regardless of the reason that a researcher is mentioned. Also, just as number of citations is an indicator of the level of impact on inside stakeholders (i.e., members of the Academy), having very few entries on Google means that outside stakeholders (i.e., people outside of the Academy) are not paying much attention (Thelwall \& Sud, 2011).

Next, we describe the sample and measures we used to gather information on impact from the perspective of both internal and external stakeholders. We also describe several types of evidence regarding the validity of our measures. We also report results pointing to the conclusion that scholarly impact is a multidimensional construct and that the impact of our scholarly research on internal stakeholders cannot be equated with impact on external stakeholders.

\section{Method}

Our targeted population consisted of the 550 management scholars in Podsakoff et al.'s (2008) Table 9, which includes an alphabetical list of the most influential scholars in the field of management based on total number of citations received between 1981 and 2004. Several studies have documented the relative impact of scholars in specific subfields, including international business (e.g., Chan, Fung, \& Leung, 2009; Morrison \& Inkpen, 1991), strategic management (e.g., Furrer, Thomas, \& Goussevskaia, 2008), and entrepreneurship (e.g., Shane, 1997). In contrast, Podsakoff et al. (2008) provided a list of the most impactful scholars in the entire field, focusing on citations received by each author based on articles published in 30 journals between January 1, 1981, and June 30, 2004-making their list the most comprehensive and also the most current. As we describe next, our final sample included 384 from the population of 550 for whom we were able to 
obtain information regarding total number of Google entries on .edu and non-.edu domains (as indexed by Google's search engine) and total number of citations (as indexed by Web of Science).

\section{Impact Outside the Academy: Google Entries}

The process of collecting data for our study using Google involved five steps and decision points to ensure the construct validity of our measure of impact outside the Academy. Our methodology followed best-practice recommendations derived from the field of information science and technology, specifically a subfield of study called webometric research (Thelwall \& Sud, 2011).

First, for each of the 550 targeted scholars, we used the full and complete name in quotation marks as the search term. For example, the first 10 of the 550 names are, in alphabetical order, "Eric Abrahamson," "Phillip L. Ackerman," "Paul S. Adler," "Herman Aguinis," "Gautman Ahuja," "Icek Ajzen," "Ralph A. Alexander," "Natalie J. Allen," "Mats Avelsson," and "Terry L. Amburgey." Based on the first few searches, we learned that using full names in quotation marks avoided finding pages that may not relate to a particular researcher. In other words, using names without quotations, or without the middle initial, leads to potential measurement contamination in our results (i.e., false positives). For example, using Eric Abrahamson instead of "Eric Abrahamson" would lead to the inclusion of pages mentioning "Eric Olger" and "David Abrahamson," and consequently Eric Abrahamson would be credited additional entries spuriously.

Second, to gather evidence regarding the validity of our measure, we compared results based on google.com (the American version of Google) with google.es (the Spanish version of Google). Consistency in results would provide evidence regarding convergent validity. Reassuringly, we found that the total number of pages was identical regardless of the specific version of Google used. However, although irrelevant for the goals of our study, we found that the order in which the entries are listed did vary; for example, pages in Spanish were listed earlier using google.es than google.com. Given the interchangeability of re- sults regarding total number of entries, we chose to collect our data using google.com.

Third, the information science and technology literature suggests that the most important threat to the validity of results based on webometric research is the presence of spurious matches (Thelwall \& Sud, 2011). Specifically related to our study, Google may return results that should not be credited to the specific author in question. Accordingly, after searching for each name in quotation marks, we manually inspected the first 50 pages returned for each individual to ascertain whether any of these pages were the result of measurement contamination (i.e., a page that did not refer to the scholar in question-a false positive). For example, we found that there are many individuals with the exact same first and last name as "Eric Abrahamson," and many of them are referred to on many sites on the Web. There are too many idiosyncratic and likely nonreplicable judgment calls involved in confidently ascertaining whether a particular Web page for an author with a common first and last name refers to the particular author we were looking for or to another person. Thus, we used the criterion of $5 \%$ of spurious entries to exclude authors. In other words, if our search led to three or more spurious entries (i.e., pages falsely attributed to the author in question) in the first 50 pages, that author was excluded from our database. Although this decision meant that we were not able to gather information on all 550 authors, it minimized spurious results and maximized the integrity of our data, which would have been contaminated had we included entries that did not refer to a particular author. Using this process led to a sample of 391 of the 550 authors included in the targeted population.

Fourth, the indexing system used by Google, which is called Caffeine, constantly updates the URL index, and it is designed to return pages in order of relevance. Google provides the total number of pages resulting from any given search, and we used these totals in our analyses to assess each author's impact beyond the Academy. Note that the number of pages returned by Google may fluctuate given that the search procedure prioritizes speed over precise accuracy (Cronin, Snyder, 
Rosenbaum, Martinson, \& Callahan, 1998; Webmaster tools help, 2012). To use a more stable estimate of the total number of Google entries for each author, we quadrupled our data-gathering efforts and collected data over four separate and independent occasions. Specifically, we repeated our data collection for each of the scholars four times during November 2011.

Finally, an important aspect of our data collection efforts is that we distinguished between .edu and non-.edu pages. This is an important distinction because edu pages reside on servers that belong to academic institutions; pages without the .edu domain likely reside on non-academic servers. Thus, a comparison of their numbers is particularly useful for understanding impact inside and outside the Academy.

\section{Impact Inside the Academy: Citations}

We used the Web of Science database to obtain the total number of times each author was cited from January 1981 through October 2011. We replicated Podsakoff et al.'s methodology and considered the total number of citations for each author's publications classified as articles, notes, or reviews published since 1981. However, a difference between Podsakoff et al. (2008) and our study is that we did not restrict citations to those articles published in particular journals. Rather, because we wanted to assess the broadest possible impact of each of these influential scholars, not just their impact based on a subset of journals, we obtained the total number of citations received by each author regardless of the specific journal in which the cited article was published. Note that our more inclusive assessment of citations led to the consideration of articles published in journals that were excluded from Podsakoff et al.'s analysis, such as Research in Organizational Behavior, Academy of Management Perspectives, and Organization Studies.

As described by Podsakoff et al. (2008), using Web of Science to conduct searches based on author names poses some challenges; the most important is that Web of Science allows searches of last names but only initials of first and middle names. This may lead to potential false positives, which both in our study and in Podsakoff et al.'s consist of possibly attributing citations to an author when some of these citations may refer to a different author(s) with the same last name and first and middle initials. We implemented several steps to minimize the impact of this potential threat to the validity of our results. First, many of the authors included in our targeted population have a MyResearcherID number, which is a unique identifier created by Web of Science precisely to avoid spurious results. Thus, when available, we used this tool to identify the publications authored by those specific scholars.

Second, for each remaining author, we examined the actual full-text publications when available to confirm a match with the intended author's affiliation (i.e., department and university) as well as research domains (e.g., organizational studies versus physics, chemistry, and other unrelated fields). We considered the fact that some authors have changed affiliations over the years. In some cases, it was not possible to separate publications authored by different people with the same last name and first and middle initials. In the end, we were unable to clearly distinguish seven of the 391 targeted authors from others with the same name. To avoid possible upward bias in the total number of citations for these seven authors, we eliminated them from our sample. These individuals are Ming-Jer Chen, Jerald Greenberg, Ranjay Gulati, Rabindra Kanungo, Yadong Luo, Kok Yee Ng, and Stephen G. West. Thus, our final sample size of authors for whom we had information on both number of Google entries and number of citations was 384 .

Another challenge involved in using Web of Science to gather information on number of citations is that some authors used different names in different articles. For example, some authors used both a first and a middle name in some sources but only their first name in others. In addition, some authors used a hyphenated last name in some articles and not in others, and some authors used a totally different last name across sources (this was the case for some female authors who used their maiden name in some publications and later their married name in others). To minimize this threat to the validity of our results, we conducted searches using all possible name variations for 
each author to ensure that our authors matched the ones included in Podsakoff et al.'s Table 9.

\section{Control Variables: Number of Years Since Receiving Doctorate and Number of Articles}

Our analyses included two control variables that past research suggests are related to our focal dependent variables (i.e., number of citations and number of Google entries). First, we collected information regarding number of years since each author received his or her doctoral degree. We were able to obtain this information from Podsakoff et al.'s Table 9. Note that this information was available for 377 of the 384 authors for whom we had information on Google entries and citations. Second, we used Web of Science to gather information on number of publications authored by each scholar. As noted earlier, this includes the total number of articles, notes, and reviews published from January 1981 through October 2011.

\section{Results}

In this section, we first describe evidence in support of the reliability and validity of our measures. Then, we report substantive results regarding the prediction of .edu and non-.edu Google entries using number of years since receiving a doctorate, number of publications, and number of citations as predictors. We also report results of a constructive replication study in which we used h-index scores instead of total number of citations as a predictor. Finally, we describe results regarding the potential moderating effects of number of years since earning a doctorate, field of study (i.e., business policy and strategy, organizational behavior, organization and management theory, and human resource management), and Academy of Management membership (i.e., yes versus no) on the ability of citations to predict .edu and non.edu entries.

\section{Reliability and Validity Evidence}

As evidence regarding the reliability of number of Google pages, we computed test-retest reliability coefficients between all pairs involving our four waves of data collection for total Google entries (i.e., non-.edu and .edu domains combined) and for entries on non-.edu and .edu domains sepa- rately. Given that we collected Google data over four different occasions, we computed $k(k-1)$ / $2=6$ unique test-retest reliability coefficients (where $k=4$, which is the number of data collection waves). For the total number of Google entries, the mean test-retest reliability based on the six coefficients was $.9932(\mathrm{SD}=.0039)$. For non-.edu domains, the mean test-retest reliability based on the six coefficients was .9925 (SD $=.0043)$. Finally, for .edu domains, the mean test-retest reliability based on the six coefficients was $1.0(\mathrm{SD}=0)$. In short, this reliability evidence regarding the stability of Google entries over time provides justification for computing an average based on the total number of Google entries across the four data collection waves, and we used such averages in all of our substantive analyses.

Descriptive information on our sample of 384 scholars indicates that the mean number of citations is 2,302.73 (median $=1,748.50, \mathrm{SD}=$ $1,882.05)$ and the mean number of Google entries is 191,496.61 (median = 74,837.50, $\mathrm{SD}=339,684.84)$. Regarding Google pages, the mean number of .edu entries is 4,427.58 (median $=1,805.00, \mathrm{SD}=11,091.83)$, and the mean number of non-.edu entries is 187,069.03 (median $=71,931.25, \mathrm{SD}=333,038.40)$. Regarding the two control variables, the mean number of articles published is 35.69 (median $=31$, $\mathrm{SD}=25.59)$, and the mean year when authors received their doctorates is 1982 (median $=1983$, $\mathrm{SD}=$ 9.88).

Table 1 includes correlations between our focal variables. As would be expected, the correlation between total number of articles and total number of citations is high (.503), meaning that there is an overlap of $25 \%$ in the variance between these two variables. This finding replicates previous results showing that although quantity of articles matters in terms of number of citations, it is far from being a perfect predictor (Simonton, 1997). Thus, the congruence between this result and past research provides additional evidence in support of the construct validity of our measures. Also as expected, our second control variable, number of years since earning a doctorate, is correlated with number of citations (.256). 


\section{Table 1}

\section{Correlations Between Study Variables}

\begin{tabular}{|l|r|r|r|r|r|c|c|}
\hline & \multicolumn{1}{|c|}{ M } & \multicolumn{1}{c|}{ SD } & 1 & 2 & 3 & 4 & 5 \\
\hline .edu entries & $4,427.582$ & $11,091.829$ & - & & & & \\
\hline non-.edu entries & $187,069.031$ & $333,038.403$ & .589 & - & & & \\
\hline Google entries (.edu and non-.edu combined) & $191,496.613$ & $339,684.844$ & .610 & 1.000 & - & & \\
\hline Citations & $2,302.730$ & $1,882.045$ & .378 & .166 & .175 & - & \\
\hline Articles & 35.690 & 25.585 & .260 & .152 & .158 & .503 & - \\
\hline Years since doctorate earned & 28.290 & 9.884 & .264 & .205 & .209 & .256 & .223 \\
\hline
\end{tabular}

Note: All correlations are statistically significant at the .01 level. $N=377$ for statistics involving years since doctorate earned; $N=384$ for statistics not involving years since doctorate earned.

Results in Table 1 also show a positive relationship between total number of citations and total number of entries on .edu domains: $r(382)=.378$, $p<.001$, which implies that total number of citations explains $14.29 \%$ of variance in number of .edu Google entries. We expected a positive correlation between these two variables because, similar to number of citations, number of pages residing on edu domains indicates whether other academics and academic institutions in general are paying attention to someone's research. This positive correlation coefficient also provides evidence regarding the validity of our Google measure of impact (i.e., convergent validity evidence).

Finally, we conducted additional analyses to gain a deeper understanding of the measure of impact outside the Academy. Specifically, Google provides a breakdown of the entries based on relevant categories: (a) images, (b) videos, (c) news, (d) shopping, (e) books, and (f) blogs. We collected data for each of the 384 individuals in our sample broken down into these categories. We used these data to conduct an exploratory factor analysis following best-practice recommendations offered by Hayton, Allen, and Scarpello (2004) and Conway and Huffcutt (2003) to understand possible underlying dimensions. Our approach involved a principal axis factor analysis with oblimin rotation to allow factors to be intercorrelated. The break in the scree plot, extracted eigenvalues, factor loadings, cross-factor loadings, and percentage of variance explained by the factors all suggested a two-factor solution as follows (factor loadings are in parenthesis): (a) images (.92), shopping (.60), and books (.66); and (b) videos (.96), news (.67), and blogs (.68). Moreover, these two factors are correlated with each other (i.e., $r=.38, p<.05)$.

Factor 1 seems to relate to publications and activities outside the Academy-for example, the publication of popular-press books. Factor 2 seems to relate to the extent to which the media and other stakeholders outside the Academy are paying attention. As expected, a correlation of .38 between the two factors suggests that reaching out to audiences outside the Academy is related to the attention received from the media and other external stakeholders. In sum, these results indicate that the number of Google entries is related to scholars' outreach activities outside the Academy as well as the effect of such activities (i.e., the extent to which outside stakeholders pay attention to such activities). Thus, these results confirm that number of Google entries is an indicator of impact outside the Academy.

\section{Predicting Number of Citations Based on .edu and Non-.edu Entries}

The correlation between total number of citations and total number of pages residing on non-.edu domains is $r(382)=.166, p<.001$, which implies that the total number of citations explains only $2.76 \%$ of variance in non-.edu Google entries. Moreover, a test of dependent correlations comparing the relationship between total number of citations and .edu entries versus the relationship between total number of citations and non-.edu entries indicated that these correlations do indeed differ: $z(N=384)=4.34, p<.001$. In other words, the explanatory power of total number of citations is much smaller when predicting non- 
.edu $(2.76 \%$ of variance explained) versus .edu (14.29\% of variance explained) Google entries.

We conducted more in-depth multiple regression analyses to gain a better understanding of the relationships among Google entries (.edu and non-.edu domains), number of articles, number of years since doctorate, and number of citations. Our goal with these analyses was to understand the relative fit of a model predicting number of entries on non-.edu pages compared to a model predicting number of entries on .edu pages based on the same predictors (i.e., number of articles, number of years since doctorate, and number of citations).

Table 2 summarizes multiple regression analysis results predicting number of .edu entries. In Model 1, we first entered the two control variables: number of years since doctorate earned and number of articles. In Model 2, we added a third predictor: number of citations. As shown in Table 2, both predictors (i.e., control variables) in Model 1 are related to number of .edu entries and, combined, explain 11\% of variance. In Model 2, adding number of citations as a third predictor results in an additional $7 \%$ of variance explained above and beyond that predicted by the control variables in Model 1 (i.e., $\Delta F[1,372]$ $=29.00, p<.001$ ).

Table 3 summarizes multiple regression analysis results predicting number of non-.edu entries using the same three predictors and in the same order as we did previously regarding the prediction of .edu entries. Results summarized in Table 3 are quite different from those in Table 2 in that the fit of the models is substantially worse. Specifically, total variance explained in non-.edu pages by all three predictors is only $5.8 \%$ (versus $18 \%$ in the previous model), and the variance explained by citations above and beyond the control variables is not statistically significant and only .5\% in magnitude (versus $7 \%$ and $p<.001$ in the previous model). As expected based on these results, Table 3 shows that the regression coefficient for number of citations is not statistically significant for predicting number of non-.edu entries.

\section{Constructive Replication Study Using h-index Scores}

As an additional check regarding the robustness of our results, we redid all regression analysis using h-index scores instead of total citations, thereby replicating analyses reported in Tables 2 and 3. Specifically, we gathered data regarding the h-index (see also Harzing \& van der Wal, 2009; Hirsch, 2005) as reported by Web of Science. As noted by Hirsch (2005), after whom the h-index is named, a scholar with an index of $\mathrm{h}$ has published $\mathrm{h}$ articles, each of which has been cited at least $\mathrm{h}$ times. Thus, the h-index takes into account both quality and quantity of publications.

Reassuringly, substantive conclusions remained unchanged. For example, the correlation between $\mathrm{h}$-index scores and number of Google entries on .edu domains is .31, whereas the correlation between h-index scores and number of Google entries on non-.edu domains is .17. The difference between these correlations is statistically significant, $z=1.99, p<.05$. In other words, results based on our constructive replication study using $\mathrm{h}$-index instead of total number of citations continue to indicate that impact inside the Academy cannot be equated with impact outside the Academy. Note that the consistency in results based on different citation-based metrics is not surprising. Specifically, the regression analysis reported in Tables 2 and 3 used number of articles as a control variable; therefore, our analyses did take into account the number of papers the individuals have published. Given the convergence in the results, we focus on total citations because doing so allows our results to be directly comparable to those reported by Podsakoff et al. (2008), who also used total citations. In other words, Podsakoff et al.'s rankings are based on total citations (and so are our Tables 4 through 6, described below).

\section{Examination of Potential Moderating Effects}

We examined whether there is a stronger relationship between citations and non-.edu pages for more junior scholars compared to more senior ones. This type of analysis is informative regarding the possibility that the relationship between impact inside and outside the Academy is stronger for junior than for senior scholars-perhaps suggesting a narrowing of the science-practice gap. To do so, we used non-.edu pages as the criterion variable and the same three predictors as in the previous analyses: number of articles, number of 


\section{Table 2}

\section{Multiple Regression Analysis Predicting Number of Google Entries Residing on .edu Domains}

\begin{tabular}{|c|c|c|c|c|c|c|}
\hline \multirow[b]{2}{*}{ Model } & \multicolumn{3}{|c|}{1} & \multicolumn{3}{|c|}{2} \\
\hline & $b$ & SE & $\beta$ & $b$ & SE & $\beta$ \\
\hline Intercept & $-5,780.41$ & $1,708.80$ & & $-6,258.44$ & $1,650.60$ & \\
\hline Years since doctorate earned & 246.33 & 56.58 & .22 & 195.31 & 55.39 & .17 \\
\hline Number of articles & 91.25 & 21.90 & .21 & 31.31n.s. & 23.87 & $.07 n . s$ \\
\hline Number of citations & & & & 1.76 & .33 & .30 \\
\hline$R^{2}$ & .11 & & & .18 & & \\
\hline$\Delta R^{2}$ & & & & .07 & & \\
\hline FChange $(\Delta A)$ & $23.38^{* *}$ & & & $29.00^{* *}$ & & \\
\hline
\end{tabular}

Note: $N=377, b=$ unstandardized regression coefficient, $S E=$ standard error, $\beta=$ standardized regression coefficient, ** $p<.01$. All regression coefficients, $R^{2}$-values, and $F$ statistics are statistically significant at the .001 level, except for the one denoted as $n . s$. (i.e., $p>.05)$.

\section{Table 3}

\section{Multiple Regression Analysis Predicting Number of Google Entries Residing on Non-.edu Domains}

\begin{tabular}{|c|c|c|c|c|c|c|}
\hline \multirow[b]{2}{*}{ Model } & \multicolumn{3}{|c|}{1} & \multicolumn{3}{|c|}{2} \\
\hline & $b$ & SE & $\beta$ & $b$ & SE & $\beta$ \\
\hline Intercept & $-34,054.38$ & $52,926.93$ & & $-38,179.12$ & $52,925.82$ & \\
\hline Years since doctorate earned & $6,142.74^{* *}$ & $1,752.38^{* *}$ & $.18^{* *}$ & $5,702.48^{* *}$ & $1,775.98^{* *}$ & $.17^{* *}$ \\
\hline Total no. of articles & $1,381.98^{*}$ & $678.11^{*}$ & $.11^{*}$ & 864.78 & 765.41 & .07 \\
\hline Total no. of citations & & & & 15.14 & 10.45 & .09 \\
\hline$R^{2}$ & .052 & & & .058 & & \\
\hline$\Delta R^{2}$ & & & & .005 & & \\
\hline$F$ Change $(\Delta f)$ & $10.33^{* * *}$ & & & 2.10 & & \\
\hline
\end{tabular}

Note: $N=377, b=$ unstandardized regression coefficient, $S E=$ standard error, $\beta=$ standardized regression coefficient, ${ }^{*} p<.05, * \star p$ $<.01, * * * p<.001$.

years since doctorate, and number of citations. Then, as a second step in the analysis, we added the product term between number of years since doctorate and number of citations, which carries information regarding the potential moderating effect of years since doctorate on the relationship between number of citations and number of non.edu pages (Aguinis, 2004). Results indicated that the model with the first-order effects explained $5.8 \%$ of variance (as we described based on results shown in Table 3), and the addition of the product term did not improve the fit of the model in terms of explaining additional variance in the number of non-.edu pages, $\Delta R^{2}=.00, F(1,372)=.001$, $p=.98$. In short, the relationship between number of citations and number of non-.edu pages does not differ based on the year when scholars received their doctorates.
We collected additional data and implemented additional analyses to understand whether impact is related to field of study. To do so, we manually searched each of the 384 individuals in our database in the Academy of Management (AOM) membership directory and recorded each person's membership by focusing on the AOM's four largest divisions as of February 2012: Organizational Behavior (OB, 5,835 members), Business Policy and Strategy (BPS, 4,801 members), Organization and Management Theory (OMT, 3,735 members), and Human Resource Management (HRM, 3,384 members). Also, when appropriate, we recorded whether a particular individual was not an AOM member at all. This categorization allowed us to investigate whether the impact inside or outside the Academy varies based on an individual's primary domain/field. We conducted 
ANOVAs with number of citations and Google entries (both .edu and non-.edu domains) as the dependent variables and division membership as the independent variable. To do so, we created dummy-code variables to represent membership (yes or no) in each of the four aforementioned AOM divisions and membership in AOM in general, for five dummy variables. Results based on eight separate tests regarding AOM division membership (i.e., two dependent variables and four independent variables) indicated no statistically significant differences. Also, we conducted an additional ANOVA with number of citations as the dependent variable and AOM membership (i.e., $\mathrm{AOM}$ member yes versus $\mathrm{AOM}$ member no) as the independent variable and also found a statistically nonsignificant result. As a 10th test, an ANOVA with number of Google entries as the dependent variable and AOM membership (i.e., $\mathrm{AOM}$ member yes versus $\mathrm{AOM}$ member no) as the independent variable yielded an $F$ statistic that barely surpassed the .05 statistical significance cutoff, $F(1,382)=4.83, p=.03$. Given 10 tests and a .05 type I error rate, we expected that .5 tests (i.e., $10 \times .05)$ would be statistically significant by chance alone (i.e., a false positive). Thus, given that only one of 10 tests was statistically significant, and with a borderline p-value of .03, we are hesitant to attribute a substantive meaning to this result, particularly in light of the additional statistically nonsignificant results we describe next.

Finally, as an additional set of analyses, we replicated all regression models reported in Tables 2 and 3, adding an additional last step in the models including the product term between AOM membership and number of citations. A statistically significant product term would suggest that AOM membership moderates the relationship between impact inside (i.e., citations) and outside (i.e., Google entries) the Academy (Aguinis, 2004). All such moderating effect tests were statistically nonsignificant. In sum, based on new data and analysis, the conclusion is that field of study does not seem to matter in terms of impact, at least based on a distinction based on AOM division membership (i.e., OB, BPS, OMT, and
HRM) and AOM membership in general (i.e., yes versus no).

\section{Discussion}

It is no exaggeration to state that the field of management is obsessed with the assessment of the impact of our scholarly work (Adler \& Harzing, 2009). Numerous articles have been written on the relative impact of individual scholars, individual articles, departments, universities, and even entire fields. Moreover, the quality of scholarly journals is often judged on their relative impact. Also, rankings as well as tangible and intangible rewards are often distributed to individual scholars and even departments based on such impact-based analyses. Despite the apparent diversity of such analyses of impact and a substantial body of research on these issues, the common denominator is their reliance on number of citations. The operational definition of impact is uniformly narrow and deficient from a psychometric perspective because an examination of citations focuses exclusively on the impact of our research on other academics.

Using stakeholder theory as a theoretical backdrop (Freeman, 1984), the field of management seems to be primarily concerned with the impact of our scholarly work on internal stakeholders (i.e., other members of the Academy). We are not aware of published research attempting to assess the impact of the scholarly work produced by individual scholars on external stakeholders (i.e., those outside the Academy). The lack of research regarding this issue has been noticed by the Academy of Management as a whole. Specifically, one of the four strategic intent statements refers to "professional impact: The Academy of Management encourages our members to make a positive difference in the world by supporting scholarship that matters" (Academy of Management Strategic Plan, 2012). Given this strategic intent statement, strategic objectives are to "Define professional impact and for whom" and "engage our colleagues and relevant stakeholders in a reflexive consideration and conversation about the meaning of professional impact" (Academy of Management Strategic Plan, 2012). Our study is what seems to be the first attempt to do just that. 
Our results demonstrate that scholarly impact is a multidimensional construct. Stated differently, there are different types of "scholarly impact." Specifically, the impact of our scholarly research on internal stakeholders cannot be equated with impact on external stakeholders. Results of our multiple regression analysis summarized in Table 3 indicate that number of citations is not related to number of non-.edu entries after controlling for number of years since receiving a doctorate and total number of articles. By contrast, multiple regression analyses summarized in Table 2 suggest that number of citations is related to number of .edu pages. In other words, these results suggest that number of citations and number of .edu entries are both indicators of impact on inside stakeholders-the extent to which other researchers and academic institutions, which host .edu pages, are paying attention to the work produced by particular scholars. In contrast, number of non.edu entries, which reflects the extent to which stakeholders from outside the Academy are paying attention to particular scholars, is an indicator of a different and broader type of impact. Our constructive replication study, using h-index scores instead of total number of citations, led to the same substantive conclusion. In addition, we found that number of years since earning a doctorate, field of study, and AOM membership status did not serve as moderators of the relationship between impact inside and outside of the Academy.

Podsakoff et al. (2008) provided a ranking of "the research scholars who have had the greatest impact on the field of management during the past quarter century" (p. 641). In light of our results, we reinterpret those rankings as being produced from the perspective of inside stakeholders only because they were based on number of citations. Results we have described thus far based on correlations and regression analyses, as well as the relative size of effects, demonstrate that impact inside the Academy should not be equated with impact outside the Academy.

Next, we offer another, and possibly even more compelling, way of describing our results.
Table 4 includes the list of the 384 scholars included in our study. These scholars are ranked based on both number of citations and number of non-.edu entries. This table shows important changes in the rank ordering of individuals based on whether we operationalize impact considering internal stakeholders (i.e., number of citations) or external stakeholders (i.e., number of non-.edu web pages). On average, there is a difference of 100.32 ranks between the lists based on citations and non-.edu entries. Moreover, there are 19 scholars for whom there is a difference of more than 200 ranks across the two lists. For example, Viswanath Venkatesh is ranked 27th based on citations (93rd percentile) but 308th (20th percentile) based on non.edu pages, Icek Ajzen is ranked third based on citations (99th percentile) but 273rd (28th percentile) based on non-.edu pages, and Bruce $M$. Kogut is ranked eighth in citations (98th percentile) but 267 th (30th percentile) based on non-.edu pages. Using these individuals as examples, we see that a high rank based on citations can be associated with a much lower rank based on non-.edu pages.

As noted by an Academy of Management Perspectives anonymous reviewer, these results "should give administrators pause." Please note that it is not our intention to single out specific scholars or derive any negative connotations from these results - after all, the 384 individuals included in our study are some of the most cited researchers in the entire field of management in the past 30 years or so, and we admire and celebrate this accomplishment. However, we believe these specific examples provide vivid illustrations that rankings based on impact on inside stakeholders are quite different from rankings based on impact on stakeholders outside the Academy.

Our data allow us to answer yet another interesting question: Who are the most influential scholars inside the Academy who also have an important impact outside the Academy? We used Table 4 as a starting point and selected those who are in the top 100 in both number of citations and number of non-.edu entries. The resulting set of 40 individuals is included in 


\section{Table 4}

\section{Ranking of Influential Scholars in the Field of Management Based on Number of Citations and Number of Google Pages Residing on Non-.edu Domains}

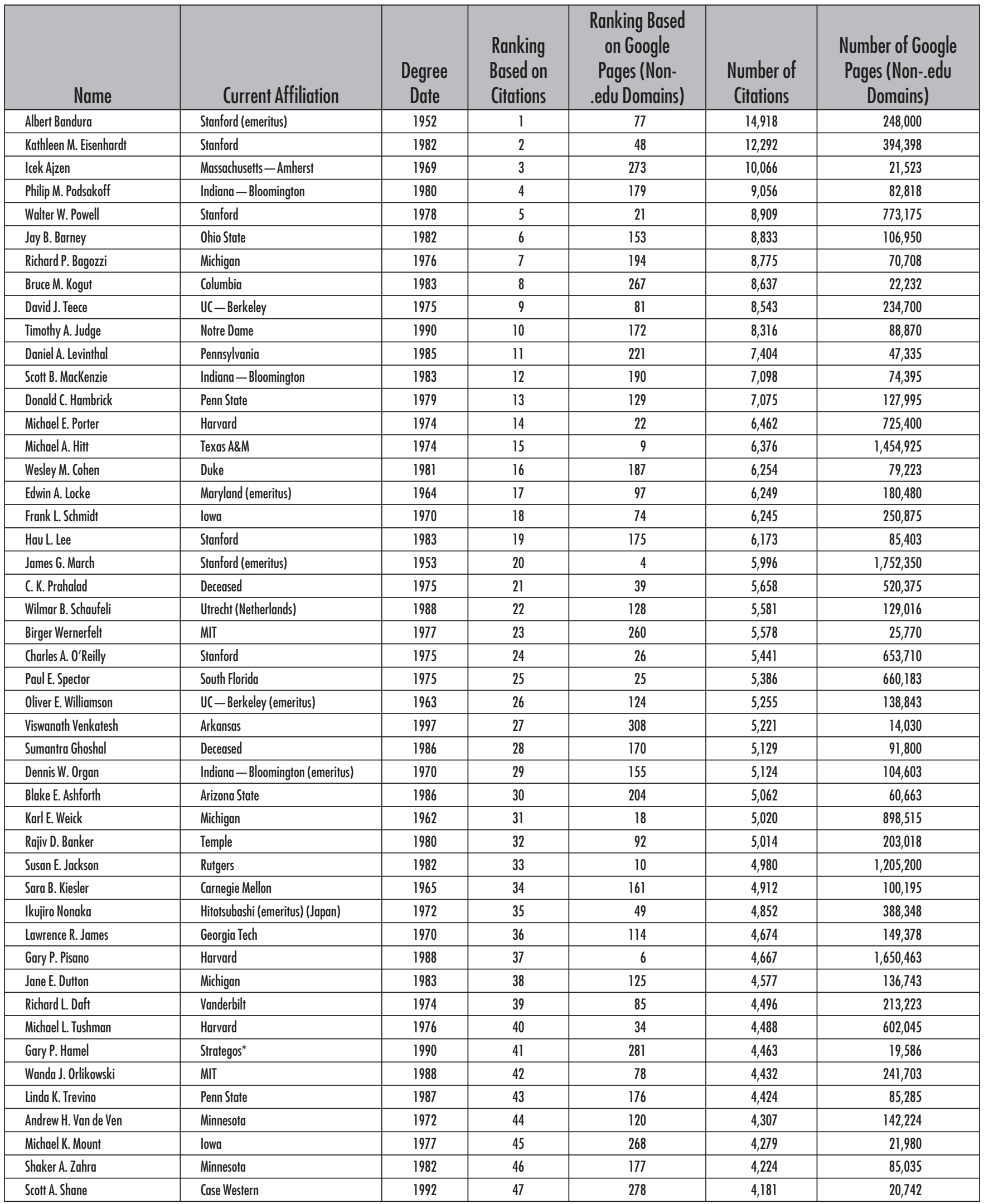




\section{Table 4}

\section{(Continued)}

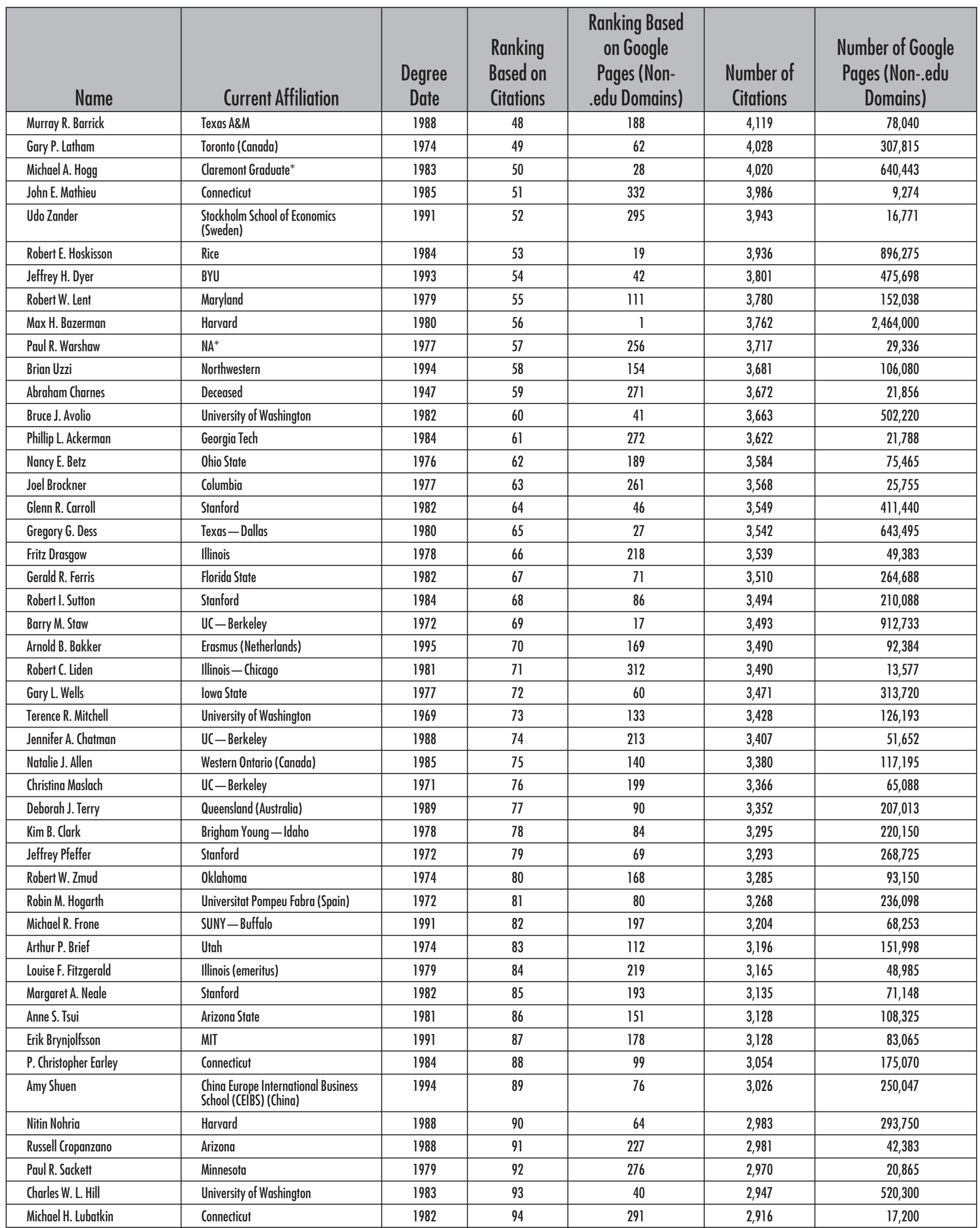




\section{Table 4}

\section{(Continued)}

\begin{tabular}{|c|c|c|c|c|c|c|}
\hline Name & Current Affiliation & $\begin{array}{c}\text { Degree } \\
\text { Date }\end{array}$ & $\begin{array}{l}\text { Ranking } \\
\text { Based on } \\
\text { Citations }\end{array}$ & $\begin{array}{l}\text { Ranking Based } \\
\text { on Google } \\
\text { Pages (Non- } \\
\text {.edu Domains) }\end{array}$ & $\begin{array}{c}\text { Number of } \\
\text { Citations }\end{array}$ & $\begin{array}{l}\text { Number of Google } \\
\text { Pages (Non-.edu } \\
\text { Domains) }\end{array}$ \\
\hline Marshall L. Fisher & Pennsylvania & 1970 & 95 & 138 & 2,912 & 119,198 \\
\hline Deniz S. Ones & Minnesota & 1993 & 96 & 222 & 2,875 & 46,664 \\
\hline Stephen R. Barley & Stanford & 1984 & 97 & 117 & 2,850 & 146,958 \\
\hline Ian C. MacMillan & Pennsylvania & 1975 & 98 & 246 & 2,828 & 34,033 \\
\hline Gerardine L. Desanctis & Deceased* & 1982 & 99 & 376 & 2,806 & 2,369 \\
\hline Scott A. Snell & Virginia & 1989 & 100 & 146 & 2,802 & 110,237 \\
\hline Denise M. Rousseau & Carnegie Mellon & 1977 & 101 & 63 & 2,794 & 305,175 \\
\hline Henry Mintzberg & MeGill (Canada) & 1968 & 102 & 37 & 2,789 & 536,800 \\
\hline LeeS. Sproull & NYU & 1978 & 103 & 162 & 2,784 & 96,280 \\
\hline Roger G. Schroeder & Minnesota & 1966 & 104 & 44 & 2,780 & 412,635 \\
\hline Daniel C. Feldman & Georgia & 1976 & 105 & 107 & 2,758 & 157,673 \\
\hline Jeffrey H. Greenhaus & Drexel & 1970 & 106 & 30 & 2,758 & 628,920 \\
\hline Sandy J. Wayne & Illinois_Chicago & 1987 & 107 & 287 & 2,730 & 17,980 \\
\hline Paul J. H. Schoemaker & Pennsylvania & 1977 & 108 & 79 & 2,729 & 237,690 \\
\hline Joel A. C. Baum & Toronto (Canada) & 1989 & 109 & 181 & 2,721 & 81,515 \\
\hline Robert H. Lengel & Texas - San Antonio & 1983 & 110 & 305 & 2,642 & 14,938 \\
\hline Susan J. Ashford & Michigan & 1983 & 111 & 262 & 2,599 & 25,710 \\
\hline Terri A. Scandura & Miami (Florida) & 1988 & 112 & 225 & 2,594 & 43,495 \\
\hline Aks Zaheer & Minnesota & 1992 & 113 & 380 & 2,555 & 1,797 \\
\hline Karen A. Jehn & Melbourne (Australia) & 1992 & 114 & 233 & 2,528 & 39,875 \\
\hline Ken G. Smith & Rhode island & 1983 & 115 & 67 & 2,504 & 285,228 \\
\hline Lynne G. Zucker & UCLA & 1974 & 116 & 289 & 2,482 & 17,663 \\
\hline F. David Schoorman & Purdue & 1983 & 117 & 277 & 2,457 & 20,844 \\
\hline Jason A. Colquitt & Georgia & 1999 & 118 & 142 & 2,456 & 112,463 \\
\hline Paul W. Beamish & Western Ontario (Canada) & 1985 & 119 & 127 & 2,448 & 132,428 \\
\hline Raphael H. Amit & Pennsylvania & 1977 & 120 & 320 & 2,448 & 11,585 \\
\hline Raymond A. Noe & Ohio State & 1985 & 121 & 94 & 2,434 & 198,337 \\
\hline George B. Graen & Illinois (retired) & 1967 & 122 & 265 & 2,410 & 23,873 \\
\hline Jeanne M. Brett & Northwestern & 1972 & 123 & 55 & 2,407 & 353,445 \\
\hline Randall S. Schuler & Rutgers & 1973 & 124 & 11 & 2,382 & $1,135,330$ \\
\hline Roger C. Mayer & North Carolina State & 1989 & 125 & 243 & 2,377 & 35,343 \\
\hline Stephan J. Motowidlo & Minnesota $^{*}$ & 1976 & 126 & 316 & 2,375 & 12,788 \\
\hline J.Stewart Black & INSEAD (United States) & 1988 & 127 & 36 & 2,355 & 573,173 \\
\hline David E. Bowen & Thunderbird & 1983 & 128 & 58 & 2,328 & 320,160 \\
\hline Mark A. Huselid & Rutgers & 1993 & 129 & 118 & 2,325 & 145,275 \\
\hline Geert Hofstede & Maastricht (emeritus) (Netherlands) & 1967 & 130 & 57 & 2,320 & 344,600 \\
\hline James D. Westphal & Michigan & 1996 & 131 & 258 & 2,273 & 27,813 \\
\hline Joseph S. Valacich & Arizona & 1989 & 132 & 61 & 2,272 & 312,755 \\
\hline G. Tomas Hult & Michigan State & 1995 & 133 & 101 & 2,264 & 171,693 \\
\hline Luis R. Gomez-Mejia & Texas A\&M & 1981 & 134 & 56 & 2,264 & 352,675 \\
\hline Joyce E. Bono & Florida & 2001 & 135 & 242 & 2,258 & 35,477 \\
\hline John D. Sterman & MIT & 1982 & 136 & 88 & 2,255 & 207,165 \\
\hline John R. Hollenbeck & Michigan State & 1984 & 137 & 183 & 2,244 & 80,815 \\
\hline Sydney Finkelstein & Dartmouth & 1988 & 138 & 72 & 2,243 & 260,655 \\
\hline Mike W. Peng & Texas-Dallas & 1996 & 139 & 29 & 2,223 & 631,755 \\
\hline Thomas H. Davenport & Babson & 1982 & 140 & 73 & 2,221 & 255,325 \\
\hline R. Duane Ireland & Texas A\&M & 1977 & 141 & 51 & 2,220 & 369,150 \\
\hline Mary A. Konovsky & Tulane & 1986 & 142 & 363 & 2,215 & 4,665 \\
\hline
\end{tabular}




\section{Table 4}

\section{(Continued)}

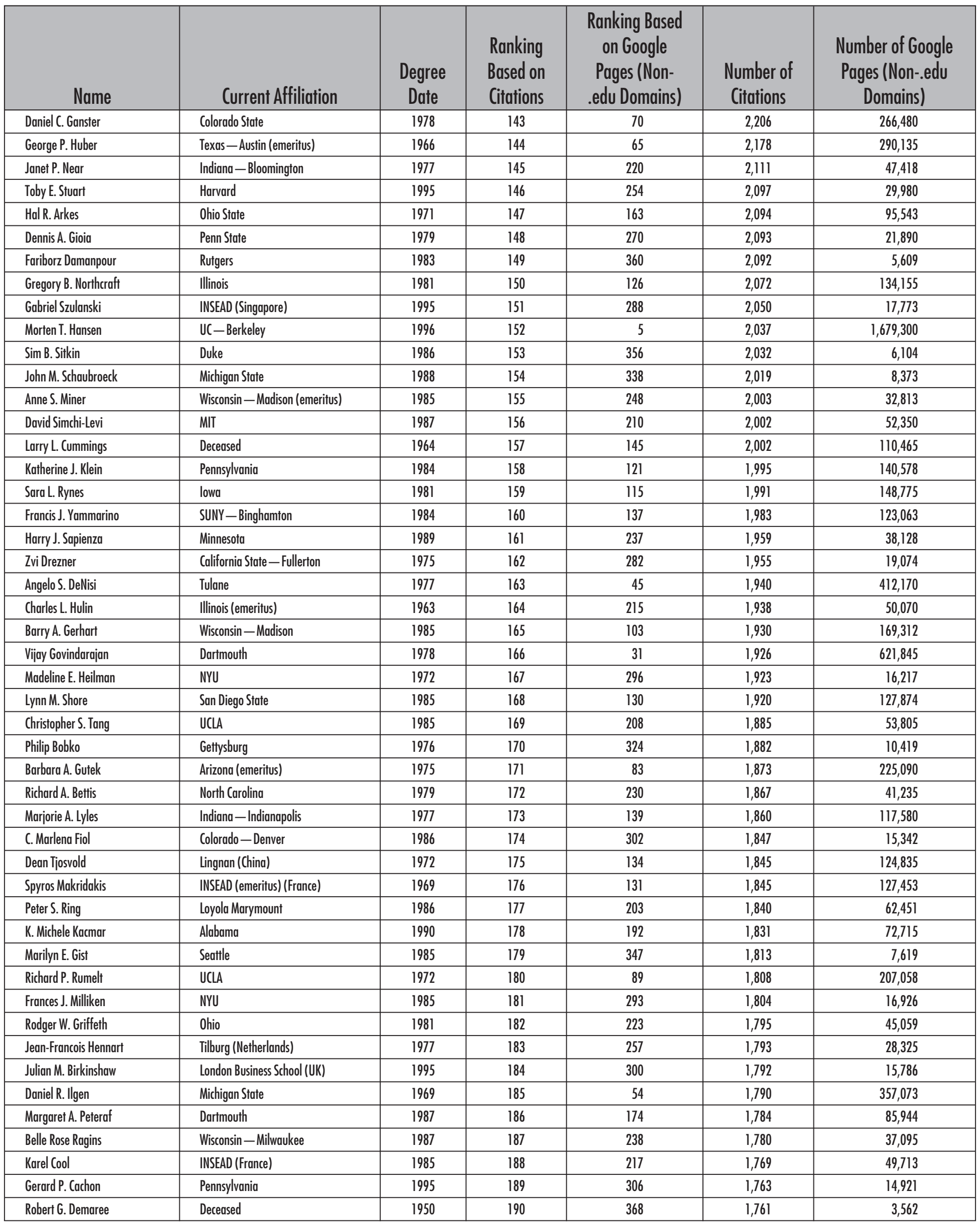


Table 4

\section{(Continued)}






\section{Table 4}

\section{(Continued)}

\begin{tabular}{|c|c|c|c|c|c|c|}
\hline Name & Current Affiliation & $\begin{array}{c}\text { Degree } \\
\text { Date }\end{array}$ & $\begin{array}{l}\text { Ranking } \\
\text { Based on } \\
\text { Citations }\end{array}$ & $\begin{array}{l}\text { Ranking Based } \\
\text { on Google } \\
\text { Pages (Non- } \\
\text { edu Domains) }\end{array}$ & $\begin{array}{c}\text { Number of } \\
\text { Citations }\end{array}$ & $\begin{array}{c}\text { Number of Google } \\
\text { Pages (Non-.edu } \\
\text { Domains) }\end{array}$ \\
\hline Arvind Parkhe & Temple & 1989 & 238 & 358 & 1,420 & 5,751 \\
\hline Cheri 0stroff & Maryland & 1987 & 239 & 335 & 1,420 & 8,821 \\
\hline Fred Mael & Mael Consulting \& Coaching & 1988 & 240 & 350 & 1,417 & 7,168 \\
\hline Jone L. Pearce & UC-Irvine & 1978 & 242 & 123 & 1,406 & 139,478 \\
\hline Steve W. J. Kozlowski & Michigan State & 1982 & 243 & 255 & 1,399 & 29,882 \\
\hline Benson Rosen & North Carolina & 1970 & 244 & 351 & 1,388 & 6,975 \\
\hline Constance E. Helfat & Dartmouth & 1985 & 245 & 239 & 1,384 & 36,448 \\
\hline Kim S. Cameron & Michigan & 1978 & 246 & 7 & 1,381 & $1,568,540$ \\
\hline Donald E. Conlon & Michigan State & 1989 & 250 & 313 & 1,343 & 13,553 \\
\hline Cristina B. Gibson & Western Australia (Australia) & 1995 & 251 & 240 & 1,314 & 35,824 \\
\hline Srilata Zaheer & Minnesota & 1992 & 252 & 357 & 1,314 & 6,034 \\
\hline Angelo J. Kinicki & Arizona State & 1982 & 253 & 327 & 1,311 & 10,029 \\
\hline Kathleen R. Conner & $N A^{*}$ & 1986 & 254 & 309 & 1,307 & 13,836 \\
\hline Heather A. Haveman & UC-Berkeley & 1990 & 255 & 286 & 1,303 & 18,077 \\
\hline Nicholas J. Beutell & lona & 1979 & 256 & 292 & 1,298 & 17,167 \\
\hline Shona L. Brown & Google, Inc.* & 1995 & 257 & 75 & 1,294 & 250,120 \\
\hline Alan D. Meyer & Oregon (emeritus) & 1977 & 258 & 109 & 1,286 & 155,218 \\
\hline Amy L. Kristof-Brown & lowa & 1997 & 259 & 374 & 1,278 & 2,914 \\
\hline Stuart L. Hart & Cornell & 1983 & 260 & 2 & 1,269 & $2,265,625$ \\
\hline M. Susan Taylor & Maryland & 1979 & 267 & 200 & 1,208 & 63,498 \\
\hline John P. MacDuffie & Pennsylvania & 1991 & 268 & 381 & 1,200 & 1,551 \\
\hline Maria L. Kraimer & lowa & 1999 & 269 & 336 & 1,195 & 8,637 \\
\hline Alan M. Saks & Toronto - Scarborough (Canada) & 1990 & 270 & 116 & 1,188 & 147,425 \\
\hline Charles R. Schwenk & $N A^{*}$ & 1980 & 271 & 144 & 1,183 & 110,473 \\
\hline Wayne F. Cascio & Colorado-Denver & 1973 & 272 & 16 & 1,181 & 932,103 \\
\hline Daniel P. Skarlicki & British Columbia (Canada) & 1995 & 273 & 198 & 1,180 & 67,496 \\
\hline George F. Dreher & Indiana - Bloomington (emeritus) & 1977 & 274 & 250 & 1,179 & 32,009 \\
\hline Herman Aguinis & Indiana -Bloomington & 1993 & 275 & 113 & 1,170 & 150,010 \\
\hline Pamela S. Tolbert & Cornell & 1983 & 276 & 108 & 1,166 & 155,530 \\
\hline David P. Lepak & Rutgers & 1998 & 277 & 285 & 1,157 & 18,115 \\
\hline Gregory H. Dobbins & Deceased & 1983 & 278 & 331 & 1,156 & 9,346 \\
\hline Ricky W. Griffin & Texas A\&M & 1978 & 279 & 3 & 1,154 & $1,979,200$ \\
\hline Amy C. Edmondson & Harvard & 1996 & 280 & 12 & 1,148 & $1,106,293$ \\
\hline Yves L. Doz & INSEAD (France) & 1976 & 281 & 15 & 1,144 & 945,305 \\
\hline Charles C. Manz & Massachusetts - Amherst & 1981 & 282 & 13 & 1,139 & $1,021,778$ \\
\hline Hal B. Gregersen & INSEAD (UAE) & 1989 & 283 & 35 & 1,135 & 597,853 \\
\hline Andrew Delios & $\begin{array}{l}\text { National University of Singapore } \\
\text { (Singapore) }\end{array}$ & 1998 & 284 & 244 & 1,099 & 34,497 \\
\hline Lois E. Tetrick & George Mason & 1983 & 285 & 96 & 1,098 & 185,260 \\
\hline
\end{tabular}


Table 4

\section{(Continued)}

\begin{tabular}{|c|c|c|c|c|c|c|}
\hline Name & Current Affiliation & $\begin{array}{l}\text { Degree } \\
\text { Date }\end{array}$ & $\begin{array}{l}\text { Ranking } \\
\text { Based on } \\
\text { Citations }\end{array}$ & $\begin{array}{l}\text { Ranking Based } \\
\text { on Google } \\
\text { Pages (Non- } \\
\text {.edu Domains) }\end{array}$ & $\begin{array}{c}\text { Number of } \\
\text { Citations }\end{array}$ & $\begin{array}{l}\text { Number of Google } \\
\text { Pages (Non-.edu } \\
\text { Domains) }\end{array}$ \\
\hline Erkko Autio & Imperial College London (UK) & 1995 & 286 & 274 & 1,085 & 21,475 \\
\hline Harry G. Barkema & Erasmus (Netherlands) & 1988 & 287 & 345 & 1,085 & 7,638 \\
\hline Linda Rhoades-Shanock & UNC-Charlotte & 2001 & 288 & 384 & 1,084 & 530 \\
\hline Elaine D. Pulakos & PDRI & 1984 & 289 & 236 & 1,079 & 38,530 \\
\hline John E. Delery & Arkansas & 1993 & 290 & 343 & 1,077 & 7,943 \\
\hline Stanley M. Gully & Rutgers & 1997 & 291 & 205 & 1,072 & 59,626 \\
\hline Peter Cappelli & Pennsylvania & 1983 & 292 & 171 & 1,069 & 89,838 \\
\hline Chris W. Clegg & Leeds (UK) & 1971 & 293 & 119 & 1,067 & 142,775 \\
\hline Anne S. Huff & $\begin{array}{l}\text { Technishe Universitït München } \\
\text { (Germany) }\end{array}$ & 1974 & 294 & 212 & 1,062 & 51,673 \\
\hline Ruth Wageman & Harvard & 1993 & 295 & 228 & 1,056 & 41,817 \\
\hline Elizabeth A. Mannix & Cornell & 1989 & 296 & 157 & 1,053 & 104,250 \\
\hline J.C. Spender & 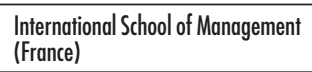 & 1980 & 297 & 315 & 1,051 & 12,918 \\
\hline Katherine R. Xin & $\begin{array}{l}\text { China Europe International Business } \\
\text { School (CElBS) (China) }\end{array}$ & 1995 & 298 & 330 & 1,051 & 9,386 \\
\hline Talya N. Bauer & Portland State & 1994 & 299 & 290 & 1,045 & 17,553 \\
\hline Kut C. So & UC-Irvine & 1985 & 300 & 333 & 1,040 & 9,040 \\
\hline Alison Davis-Blake & Michigan & 1986 & 301 & 280 & 1,038 & 20,045 \\
\hline Connie R. Wanberg & Minnesota & 1992 & 302 & 317 & 1,037 & 12,481 \\
\hline Jeffrey J. Rever & Purdue & 1997 & 303 & 159 & 1,035 & 100,510 \\
\hline Barbara B. Flynn & Indiana-Indianapolis & 1984 & 304 & 167 & 1,030 & 93,335 \\
\hline Kathryn R. Harrigan & Columbia & 1979 & 305 & 353 & 1,028 & 6,428 \\
\hline Henryl. Tosi & Florida (emeritus) & 1964 & 306 & 132 & 1,024 & 127,323 \\
\hline F. Warren McFarlan & Harvard (emeritus) & 1965 & 307 & 100 & 1,021 & 173,275 \\
\hline Stephen W. Gilliland & Arizona & 1992 & 308 & 158 & 1,018 & 101,385 \\
\hline J. Carlos Jarillo & HEC Geneva (Switzerland)* & 1986 & 309 & 226 & 1,005 & 42,974 \\
\hline Michelle A. Marks & George Mason & 1997 & 310 & 346 & 1,005 & 7,623 \\
\hline Michael G. Pratt & Boston College & 1994 & 311 & 152 & 998 & 107,230 \\
\hline Lloyd E. Sandelands & Michigan & 1982 & 312 & 251 & 992 & 31,483 \\
\hline Margarethe F. Wiersema & UC-Irvine & 1985 & 313 & 334 & 980 & 8,942 \\
\hline Deborah E. Rupp & Purdue & 2002 & 314 & 263 & 977 & 24,495 \\
\hline James W. Smither & La Salle & 1985 & 315 & 147 & 975 & 110,188 \\
\hline M. Audrey Korsgaard & South Carolinn & 1990 & 316 & 322 & 975 & 11,470 \\
\hline J. Richard Hackman & Harvard & 1966 & 317 & 136 & 967 & 123,225 \\
\hline Gina J. Medsker & HumRRO & 1993 & 318 & 301 & 964 & 15,479 \\
\hline Richard A. D'Aveni & Dartmouth & 1987 & 319 & 47 & 964 & 394,700 \\
\hline Seungin Whang & Stanford & 1988 & 320 & 196 & 961 & 69,204 \\
\hline Christopher 0. L. H. Porter & Texas A\&M & 2001 & 321 & 370 & 932 & 3,380 \\
\hline Stephen J. Mezias & INSEAD (UAE) & 1987 & 322 & 303 & 926 & 15,215 \\
\hline Mason A. Carpenter & Deceased & 1997 & 323 & 102 & 925 & 169,485 \\
\hline D. Harold Doty & Texas-Tyler & 1990 & 324 & 319 & 920 & 12,126 \\
\hline Dieter Zapf & Frankfurt (Germany) & 1988 & 325 & 148 & 911 & 110,128 \\
\hline John E. Ettlie & Rochester Institute of Technology & 1975 & 326 & 98 & 911 & 179,815 \\
\hline Janice M. Beyer & Deceased & 1973 & 327 & 185 & 910 & 79,328 \\
\hline Michael J. Wesson & Texas A\&M & 2002 & 328 & 164 & 909 & 94,510 \\
\hline W. Graham Astley & Deceased* ${ }^{*}$ & 1978 & 329 & 361 & 908 & 5,277 \\
\hline Joyce E. A. Russell & Maryland & 1983 & 330 & 231 & 890 & 41,030 \\
\hline
\end{tabular}




\section{Table 4}

\section{(Continued)}

\begin{tabular}{|c|c|c|c|c|c|c|}
\hline Name & Current Affiliation & $\begin{array}{c}\text { Degree } \\
\text { Date }\end{array}$ & $\begin{array}{l}\text { Ranking } \\
\text { Based on } \\
\text { Citations }\end{array}$ & $\begin{array}{l}\text { Ranking Based } \\
\text { on Google } \\
\text { Pages (Non- } \\
\text { edu Domains) }\end{array}$ & $\begin{array}{c}\text { Number of } \\
\text { Citations }\end{array}$ & $\begin{array}{c}\text { Number of Google } \\
\text { Pages (Non-.edu } \\
\text { Domains) }\end{array}$ \\
\hline Ramchandran Jaikumar & Deceased & 1985 & 331 & 279 & 890 & 20,666 \\
\hline Paul C. Nutt & Strathclyde (UK) & 1974 & 332 & 95 & 886 & 192,655 \\
\hline Jan W. Rivkin & Harvard & 1997 & 333 & 209 & 878 & 52,833 \\
\hline H. Kevin Steensma & University of Washington & 1996 & 335 & 340 & 868 & 8,235 \\
\hline John M. Ivancevich & Deceased & 1968 & 336 & 20 & 836 & 845,025 \\
\hline Luis L. Martins & Texas-Austin & 1997 & 337 & 310 & 832 & 13,819 \\
\hline Paul Duguid & UC-Berkeley & $n / a$ & 338 & 91 & 832 & 205,845 \\
\hline Jeffrey B. Arthur & Virginia Tech & 1990 & 339 & 321 & 829 & 11,513 \\
\hline Marvin D. Dunnette & Deceased & 1954 & 343 & 182 & 747 & 81,140 \\
\hline Harrison M. Trice & Deceased $^{*}$ & 1955 & 344 & 201 & 745 & 63,225 \\
\hline Melissa A. Schilling & NYU & 1997 & 345 & 214 & 741 & 51,481 \\
\hline Seok-Woo Kwon & UC-Riverside & 2003 & 346 & 344 & 730 & 7,795 \\
\hline Daniel G. Bachrach & Alabama & 2002 & 347 & 349 & 726 & 7,275 \\
\hline Victor E. Millar & AT\& ${ }^{*}$ & $\mathrm{n} / \mathrm{a}$ & 348 & 264 & 714 & 24,174 \\
\hline G. R. Salancik & Deceased* & 1971 & 349 & 294 & 707 & 16,842 \\
\hline Kentaro Nobeoka & Hitotsubashi, Japan & $\mathrm{n} / \mathrm{a}$ & 350 & 283 & 701 & 18,639 \\
\hline Hugh J. Arnold & Toronto (Canada) ${ }^{*}$ & 1976 & 351 & 143 & 700 & 112,313 \\
\hline Lorraine Eden & Texas A\&M & 1976 & 352 & 341 & 655 & 8,115 \\
\hline Majken Schultz & Copenhagen (Denmark) & 1988 & 360 & 241 & 621 & 35,611 \\
\hline Jesper B. Sorensen & Stanford & 1996 & 361 & 253 & 619 & 30,195 \\
\hline Glenn M. McEvoy & Utah State & 1985 & 362 & 342 & 617 & 7,982 \\
\hline James E. Bailey & George Washington & 1975 & 363 & 8 & 615 & $1,468,550$ \\
\hline Kevin G. Corley & Arizona State & 2002 & 364 & 304 & 602 & 15,095 \\
\hline Theodore Levitt & Deceased* & 1951 & 365 & 104 & 594 & 165,545 \\
\hline Julie Beth Paine & Best Buy* & 2001 & 366 & 369 & 587 & 3,439 \\
\hline Vandra L. Huber & University of Washington & 1982 & 367 & 202 & 584 & 62,889 \\
\hline Sadao Sakakibara & $N A^{*}$ & $n / a$ & 368 & 382 & 543 & 1,110 \\
\hline Sammy W. Pearson & NA & 1977 & 369 & 373 & 543 & 3,246 \\
\hline Paul A. Mabe & Georgia* & 1982 & 370 & 362 & 539 & 4,914 \\
\hline Donald M. Truxillo & Portland State & 1987 & 371 & 311 & 528 & 13,672 \\
\hline William D. Todor & $N A^{*}$ & 1979 & 372 & 325 & 517 & 10,359 \\
\hline Anthony J. Mento & Loyola-Maryland* & 1978 & 373 & 329 & 515 & 9,395 \\
\hline Richard Z. Gooding & Strategic Advantage* & 1989 & 374 & 377 & 507 & 2,349 \\
\hline Ian Mitroff & UC-Berkeley & 1967 & 375 & 68 & 495 & 282,153 \\
\hline Monica C. Higgins & Harvard & 1995 & 376 & 180 & 463 & 81,810 \\
\hline
\end{tabular}




\section{Table 4 \\ (Continued)}

\begin{tabular}{|c|c|c|c|c|c|c|}
\hline Name & Current Affiliation & $\begin{array}{c}\text { Degree } \\
\text { Date }\end{array}$ & $\begin{array}{l}\text { Ranking } \\
\text { Based on } \\
\text { Citations }\end{array}$ & $\begin{array}{c}\text { Ranking Based } \\
\text { on Google } \\
\text { Pages (Non- } \\
\text {.edu Domains) }\end{array}$ & $\begin{array}{c}\text { Number of } \\
\text { Citations }\end{array}$ & $\begin{array}{c}\text { Number of Google } \\
\text { Pages (Non-.edu } \\
\text { Domains) }\end{array}$ \\
\hline Tove H. Hammer & Cornell & 1973 & 377 & 378 & 461 & 2,215 \\
\hline Dan Karreman & Copenhagen (Denmark) & $\mathrm{n} / \mathrm{a}$ & 378 & 252 & 455 & 30,489 \\
\hline Suzanne S. Masterson & Cincinnati & 1998 & 379 & 365 & 448 & 4,351 \\
\hline Richard M. J. Bohmer & Harvard & $\mathrm{n} / \mathrm{a}$ & 381 & 298 & 389 & 16,154 \\
\hline Gerardo A. Okhuysen & Utah & 1997 & 382 & 375 & 370 & 2,669 \\
\hline Mitchell G. Rothstein & Western Ontario (Canada) & 1983 & 383 & 269 & 308 & 21,942 \\
\hline Mary Shane Connelly & Oklahoma & 1996 & 384 & 359 & 232 & 5,725 \\
\hline
\end{tabular}

Note: We obtained affiliation information from the Academy of Management membership directory for 242 individuals, Society for Industrial and Organizational Psychology membership directory for 3 individuals, Web pages for other professional associations for 5 individuals, personal Web sites for 6 individuals, university Web sites for 90 individuals, and other sources such as news Web sites and footnotes in recently published journal articles for 11 individuals. We were unable to confirm updated affiliation information for the 27 individuals denoted by an asterisk, so we used data provided by Podsakoff et al. (2008, Table 9) for them. Abbreviations: NA, not available.

As described in the methods section, our sample includes 384 of the 550 most influential scholars identified by Podsakoff et al. (2008, Table 9). The following are the individuals not included in our study: Eric Abrahamson, Paul S. Adler, Gautam Ahuja, Ralph A. Alexander, Mats Alvesson, Terry L. Amburgey, Deborah Ancona, Philip C. Anderson, William P. Barnett, Donald W. Beard, Brian E. Becker, Nathan Bennett, Robert D. Bretz, John S. Brown, Steven D. Brown, Michael J. Burke, John E. Butler, Tony Calabrese David F. Caldwell, James E. Campion, Michael A Campion, David Chan, Sayan Chatterjee, Frank Chen, Ming-Jer Chen Peter Y Chen, Susan G. Cohen, William W. Cooper, Jose M. Cortina, John L. Cotton, Catherine M. Dalton, Dan R. Dalton, T. K. Das, Fred D. Davis, Gerald F. Davis, James H. Davis, Peter S. Davis, James W. Dean, Jacques J. Delacroix, Daniel R. Denison, Alan R. Dennis, Thomas J. Donaldson, Deborah Dougherty, Thomas W. Dougherty, Jeffrey R. Edwards, Robert Eisenberger, Amir Erez, Daniel J. Farrell, Jack M. Feldman, Richard Fetter, Cynthia D. Fisher, Robert Folger, Elizabeth Frederick, Richard B. Freeman, Michael Frese, Peter H. Friesen, Stefan Gaertner, Jennifer M. George, William H. Glick, Barry M. Goldman, Michael E. Gordon, Robert M. Grant, Jerald Greenberg, Ranjay Gulati, Anil K. Gupta, Gail N. Hackett, Michael M. Harris, David A. Harrison, Christopher A. Higgins, Robert J. House, Jane M. Howell, John E. Hunter, Paul Ingram, Blake Ives, Douglas N. Jackson, Paul R. Jackson, Eric J. Johnson, Jonathan L. Johnson, Richard A. Johnson, Gareth R. Jones, Thomas M. Jones, Prashant Kale, Ruth Kanfer, Rabindra Kanungo, Ralph Katz, Tarun Khanna, John R. Kimberly, Michael P. Kirsch, Howard J. Klein, Charles E. Lance, Cynthia Lee, Dorothy Leonard, Jeffrey LePine, Kyle Lewis, Manuel London, Robert G. Lord, Yadong Luo, John G. Lynch, Jeffrey A. Martin, Phyllis A. Mason, Daniel J. McAllister, John P. Meyer, Danny Miller, William (Will) G. Mitchell, David B. Montgomery, Peter Moran, Elizabeth W. Morrison, Michael Mumford, Kevin R. Murphy, Kok Yee Ng, Christine E. Oliver, Paul S. Osterman, Nestor (Nick) Ovalle, V. Padmanabhan, James L. Perry, Lawrence H. Peters, James S. Phillips, Thomas C. Powell, Lee E. Preston, James L. Price, Vasudevan Ramanujam, E. Rhodes, Daniel Robey, Richard B. Robinson, Sandra L. Robinson, John Rohrbaugh, Jerry Ross, Philip L. Roth, Ann Marie Ryan, Jennifer K. Ryan, Katherine Ryan, Eduardo Salas, Ron Sanchez, William R. Sandberg, Neal Schmitt, Benjamin Schneider, David M. Schweiger, Brian S. Silverman, Michael C. Simon, Harbir Singh, Jitendra V. Singh, C. Ann Smith, Michael D. Smith, Robert P. Steel, Karen M. Taylor, Howard Thomas, James B. Thomas, William H. Turnley, Robert J. Vandenberg, N. Venkatraman, Chockalingam Viswesvaran, Gordon Walker, James P. Walsh, Peter Warr, James A. Waters, Jane Webster, Stephen G. West, Larry J. Williams, Robert L. Winkler, Lawrence A. Witt, Gerrit Wolf, Robert E. Wood, Mike Wright, Patrick M. Wright, Edward J. Zajac, and Dov Zohar.

Table 5. This table also includes a ranking for each individual based on a simple and unweighted arithmetic mean of the rankings based on citations and non-.edu pages. In addition to being informative regarding individual scholars, Table 5 shows that $20 \%$ (i.e., 8 out of 40 ) of these most influential individuals both inside and outside the Academy are affiliated with Stanford University. Harvard University accounts for $12.5 \%$ of such individuals ( 5 out of 40), followed by UC Berkeley with 7.5\% (3 out of 40). Thus, three universities have been able to attract and retain $40 \%$ of the 40 individuals with the highest impact both inside and outside the Academy.

Our results show that the science-practice gap does not seem to be narrowing. Specifically, number of years since receiving a doctorate degree does not serve as a moderator of the relationship between number of citations and number of non.edu pages. Although information presented in
Table 5 allowed us to identify the most impactful individuals and universities both inside and outside the Academy, those results are concerned primarily with past impact. More precisely, a perusal of Table 5 shows that 31 of those 40 most influential individuals received their doctorate degrees about 30 years ago (i.e., in 1982) or earlier. This result leads to the following question: Who are the less senior scholars in the field who are having an important impact both inside and outside the Academy?

To answer this question, we used Table 4 as the starting point and selected all individuals who received their degrees since 1991 . Our rationale was that given an academic career length of about 40 years, selecting individuals who received their degrees within the past two decades would allow us to identify those who are around their midcareer point or earlier and are likely to continue to make important contributions over at least the next two decades. Results included in Table 6 


\section{Table 5}

\section{Ranking of Influential Scholars Included in the Top 100 Ranks Based on Both Number of Citations and Number of Google Pages Residing on Non-.edu Domains (From Table 4)}

\begin{tabular}{|c|c|c|c|c|c|}
\hline Name & Current Affiliation & $\begin{array}{c}\text { Degree } \\
\text { Date }\end{array}$ & $\begin{array}{l}\text { Mean Overall } \\
\text { Ranking (1- } \\
\text { 40, Based on } \\
\text { This Table) }\end{array}$ & $\begin{array}{c}\text { Ranking Based on } \\
\text { Citations } \\
\text { (1-384, } \\
\text { Based on Table 4) }\end{array}$ & $\begin{array}{l}\text { Ranking Based on } \\
\text { Google Pages (Non- } \\
\text { edu Domains) } \\
\text { (1-384, } \\
\text { Based on Table 4) }\end{array}$ \\
\hline James G. March & Stanford (emeritus) & 1953 & 1 & 20 & 4 \\
\hline Michael A. Hitt & Texas A\&M & 1974 & 1 & 15 & 9 \\
\hline Walter W. Powell & Stanford & 1978 & 3 & 5 & 21 \\
\hline Michael E. Porter & Harvard & 1974 & 4 & 14 & 22 \\
\hline Gary P. Pisano & Harvard & 1988 & 5 & 37 & 6 \\
\hline Susan E. Jackson & Rutgers & 1982 & 5 & 33 & 10 \\
\hline Karl E. Weick & Michigan & 1962 & 7 & 31 & 18 \\
\hline Paul E. Spector & South Florida & 1975 & 7 & 25 & 25 \\
\hline Charles A. O'Reilly & Stanford & 1975 & 7 & 24 & 26 \\
\hline Kathleen M. Eisenhardt & Stanford & 1982 & 10 & 2 & 48 \\
\hline Max H. Bazerman & Harvard & 1980 & 11 & 56 & 1 \\
\hline C. K. Prahalad & Deceased & 1975 & 12 & 21 & 39 \\
\hline Robert E. Hoskisson & Rice & 1984 & 13 & 53 & 19 \\
\hline Michael L. Tushman & Harvard & 1976 & 14 & 40 & 34 \\
\hline Michael A. Hogg & Claremont Graduate & 1983 & 15 & 50 & 28 \\
\hline Albert Bandura & Stanford (emeritus) & 1952 & 15 & 1 & 77 \\
\hline Ikujiro Nonaka & Hitotsubashi (emeritus) & 1972 & 17 & 35 & 49 \\
\hline Barry M. Staw & UC-Berkeley & 1972 & 18 & 69 & 17 \\
\hline David J. Teece & UC-Berkeley & 1975 & 19 & 9 & 81 \\
\hline Gregory G. Dess & Texas-Dallas & 1980 & 20 & 65 & 27 \\
\hline Frank L. Schmidt & lowa & 1970 & 20 & 18 & 74 \\
\hline Jeffrey H. Dyer & BYU & 1993 & 22 & 54 & 42 \\
\hline Bruce J. Avolio & University of Washington & 1982 & 23 & 60 & 41 \\
\hline Glenn R. Carroll & Stanford & 1982 & 24 & 64 & 46 \\
\hline Gary P. Latham & Toronto (Canada) & 1974 & 25 & 49 & 62 \\
\hline Edwin A. Locke & Maryland (emeritus) & 1964 & 26 & 17 & 97 \\
\hline Wanda J. Orlikowski & MIT & 1988 & 27 & 42 & 78 \\
\hline Richard L. Daft & Vanderbilt & 1974 & 28 & 39 & 85 \\
\hline Rajiv D. Banker & Temple & 1980 & 28 & 32 & 92 \\
\hline Gary L. Wells & lowa State & 1977 & 30 & 72 & 60 \\
\hline Charles W. L. Hill & University of Washington & 1983 & 31 & 93 & 40 \\
\hline Gerald R. Ferris & Florida State & 1982 & 32 & 67 & 71 \\
\hline Jeffrey Pfeffer & Stanford & 1972 & 33 & 79 & 69 \\
\hline Nitin Nohria & Harvard & 1988 & 34 & 90 & 64 \\
\hline Robert I. Sutton & Stanford & 1984 & 34 & 68 & 86 \\
\hline Robin M. Hogarth & Universitat Pompeu Fabra (Spain) & 1972 & 36 & 81 & 80 \\
\hline Kim B. Clark & Brigham Young - Idaho & 1978 & 36 & 78 & 84 \\
\hline Amy Shuen & China Europe International Business School (CEIBS) (China) & 1994 & 38 & 89 & 76 \\
\hline Deborah J. Terry & Queensland (Australia) & 1989 & 39 & 77 & 90 \\
\hline P. Christopher Earley & Connecticut & 1984 & 40 & 88 & 99 \\
\hline
\end{tabular}

Note: Mean ranking is based on average of citations and Google pages residing on non-.edu domains. 


\section{Table 6}

\section{Ranking of Influential Scholars Who Received Their Degrees Since 1991 Based on Impact Inside and Outside the Academy}






\section{Table 6}

\section{(Continued)}

\begin{tabular}{|c|c|c|c|c|}
\hline Name & Current Affiliation & $\begin{array}{c}\text { Degree } \\
\text { Date }\end{array}$ & $\begin{array}{l}\text { Mean Ranking } \\
\text { (1-83, Based } \\
\text { on This Table) }\end{array}$ & $\begin{array}{c}\text { Mean Ranking } \\
\text { (1-384, From } \\
\text { Table 4) }\end{array}$ \\
\hline Monica C. Higgins & Harvard & 1995 & 49 & 278 \\
\hline Rita G. McGrath & Columbia & 1993 & 51 & 279 \\
\hline Robert P. Tett & Tulsa & 1995 & 51 & 279 \\
\hline Erkko Autio & Imperial College London (UK) & 1995 & 53 & 280 \\
\hline Giovanni Gavetti & Harvard & 2000 & 55 & 281 \\
\hline David P. Lepak & Rutgers & 1998 & 55 & 281 \\
\hline Deborah E. Rupp & Purdue & 2002 & 57 & 289 \\
\hline Lillian T. Eby & Georgia & 1996 & 57 & 289 \\
\hline Jesper B. Sorensen & Stanford & 1996 & 62 & 307 \\
\hline Gina J. Medsker & HumRRO & 1993 & 63 & 310 \\
\hline Connie R. Wanberg & Minnesota & 1992 & 63 & 310 \\
\hline Lisa Pelled Colabella & RAND Corporation & 1993 & 65 & 312 \\
\hline Katherine R. Xin & China Europe International Business School (CEIBS) (China) & 1995 & 66 & 314 \\
\hline Amy L. Kristof-Brown & lowa & 1997 & 67 & 317 \\
\hline John E. Delery & Arkansas & 1993 & 67 & 317 \\
\hline Luis L. Martins & Texas-Austin & 1997 & 69 & 324 \\
\hline John P. MacDuffie & Pennsylvania & 1991 & 70 & 325 \\
\hline Michelle A. Marks & George Mason & 1997 & 71 & 328 \\
\hline Kevin G. Corley & Arizona State & 2002 & 72 & 334 \\
\hline Daniel G. Bachrach & Alabama & 2002 & 79 & 348 \\
\hline Julie Beth Paine & Best Buy & 2001 & 80 & 368 \\
\hline Mary Shane Connelly & Oklahoma & 1996 & 81 & 372 \\
\hline Suzanne S. Masterson & Cincinnati & 1998 & 81 & 372 \\
\hline Gerardo A. Okhuysen & Utah & 1997 & 83 & 379 \\
\hline
\end{tabular}

Note: Mean ranking is based on averaging citations and Google pages residing on non-.edu domains using information included in Table 4. As described in the methods section, our sample includes 384 of the 550 most influential scholars identified by Podsakoff et al. (2008, Table 9). The following are the individuals who received their doctorate degrees since 1991 but were not included in our study: Gautam Ahuja, Tony Calabrese, David Chan, Frank Chen, Peter Y. Chen, Jose M. Cortina, Catherine M. Dalton, James H. Davis, Alan R. Dennis, Amir Erez, Richard Fetter, Stefan Gaertner, Barry M. Goldman, Ranjay Gulati, Paul Ingram, Jonathan L. Johnson, Richard A. Johnson, Prashant Kale, Tarun Khanna, Jeffrey LePine, Kyle Lewis, Yadong Luo, Jeffrey A. Martin, Daniel J. McAllister, Peter Moran, Elizabeth W. Morrison, Kok Yee Ng, Sandra L. Robinson, Jennifer K. Ryan, Katherine Ryan, Ron Sanchez, Brian S. Silverman, Michael C. Simon, William H. Turnley, and Chockalingam Viswesvaran.

show that $7.3 \%$ of individuals are affiliated with Harvard (6 out of 83 ), about $6 \%$ with Minnesota ( 5 out of 83 ), and $3.6 \%$ with Iowa (3 out of 83 ) and Rutgers (also 3 out of 83). Given behavioral consistency theory, which is the foundational approach for predicting future behavior based on past behavior in the field of human resource management (Cascio \& Aguinis, 2011), Table 6 provides useful information regarding the anticipated future impact of specific individual scholars as well as universities on both inside and outside stakeholders. 


\section{Implications for Future Research}

Our results have several implications for future research and theory development regarding scholarly impact. First, future research attempting to assess the relative impact of individual scholars, departments, universities, journals, and fields should consider the multidimensional properties of the impact construct. Our results indicate that impact inside the Academy should not be equated with impact outside the Academy. Much work has been done regarding the determinants of impact inside the Academy, including such predictor variables as number of publications in certain journals, mentoring relationships, university where the degree was obtained, university where each individual held his or her first academic job, number of publications, methodological approach used, and several other factors (e.g., Aguinis et al., 2011; Baldi, 1998; Endler, Rushton, \& Roediger, 1978; Ilgen, 2007; Judge et al., 2007; Leung, 2007; Molina-Azorin, 2012; Partington \& Jenkins, 2007). Despite this voluminous body of work, we are not aware of empirical research on determinants of impact outside the Academy (but, for a conceptual treatment of the impact of journal editors on external stakeholders, see Aguinis \& Vaschetto, 2011).

Results included in Tables 5 and 6 provide a good first step toward a program of research aimed at understanding impact beyond the Academy because they identify individuals who are impactful both inside and outside the Academy. Future research can target these individuals to collect data on why and how they have been able to achieve such a high level of impact among internal and external stakeholders. Related to this issue, it would be interesting to investigate fluctuations over time regarding the relative impact of our scholarship outside the Academy. For example, does the relative impact outside the Academy remain fairly constant over people's career spans? In other words, what is the relative role of individual differences (e.g., personality, abilities, values) and context in affecting an individual's impact outside the Academy over time? Are there specific events such as participating in executive education programs or writing a popular-press book that may trigger an increase in impact? Are there certain programs and universities that encourage a dual internal-external stakeholder impact more than others? Is this type of encouragement derived from specific organizational cultures and values? What is the role of a university's public relations/media unit in affecting a scholar's impact outside the Academy? Why and how have some universities been able to attract and retain such a disproportionately large number of scholars who have had a very high degree of impact both inside and outside the Academy? Our article represents only a very first and nascent step but also opens the door for numerous research avenues addressing these and other issues around scholarly impact outside the Academy.

Second, our measure of impact outside the Academy consisted of the total number of Google pages, particularly those residing on non-.edu domains. From a construct validity standpoint, this operational definition of impact is very similar to using total number of citations as the operational definition of impact inside the Academy. Both measures are unidimensional and broad, based on a simple count, and indicative of impact regardless of the reason for such impact. We followed bestpractice recommendations derived from the field of information science and technology, specifically webometric research, to collect our Webbased data. In addition, we collected data over four separate occasions and found support for the reliability (i.e., test-retest) of the resulting scores. Nevertheless, our study included one measure of external stakeholder impact only-and this measure is based only on information that is visible on the Internet. Thus, an additional direction for future research is the development and validation of additional measures of impact outside the Academy.

Third, our database included the most influential scholars in the field over the past three decades. As such, our data did not include the full range of citations we would have observed had we used a more inclusive targeted population-for example, all members of AOM. However, our substantive conclusions would remain the same even if we included a broader sampling strategy. The reason is that our analyses included a com- 
parison of the relative relationship between citations and .edu pages versus citations and non-.edu pages. Accordingly, the variance of citations remained constant across all analyses summarized in Tables 1 through 3. Using a broader sample would have resulted in a larger variance, but such variance would have similarly remained constant across the analyses.

\section{Implications for Practice}

Our results indicate that top performers in terms of impact inside the Academy do not necessarily have a similarly high level of impact outside the Academy. In fact, as seen in Table 4, a small minority of superstar performers have accumulated many citations-many more than most other people. Similarly, a small minority of superstar performers have accumulated many non-.edu pages-many more than most other individuals in our study. Moreover, an even smaller group of 40 scholars are among the top 100 most impactful individuals both inside and outside the Academy (see Table 5). These results are consistent with a general theory of individual performance across domains ranging from athletics to academic and political performance (O’Boyle \& Aguinis, 2012). Individual performance is not normally distributed; it follows a Pareto or power law distribution such that a small minority of performers account for the majority of outputs - be it publications, citations, basketball points, baseball home runs, football touchdowns, successful political campaigns, Emmy-award nominations, Pulitzer Prizes, Rolling Stone top-500 songs, or books on the New York Times bestseller list (O'Boyle \& Aguinis, 2012).

An important implication for practice is the question of how to manage and reward the performance of these superstars as well as faculty in general. Specifically, universities may have to rethink the implementation of performance management systems. For example, if a university emphasizes number of citations as an indicator of performance, as is the case in many institutions in the United States regarding decisions to promote associate professors to the full professorial rank, it should not necessarily expect that individuals will have a similarly important impact on outside stakeholders.

Many universities publicly promote mission, vision, and value statements that include a consideration of impact on outside stakeholders. Organizations that provide accreditation to business schools, such as the Association to Advance Collegiate Schools of Business (AACSB), consider the congruence between such statements and actual practices. Given our results, universities that wish to have an impact on outside stakeholders, and make this explicit in their mission and vision statements, should implement performance management practices that allow for the assessment of the extent to which these statements are actualized. Otherwise, a lack of congruence between mission, vision, and value statements and performance management practices may risk a failure to receive accreditation.

This particular implication for practice addresses the more general issue of how to design faculty reward systems that attempt to promote other types of performance, such as informal technology transfers (Link, Siegel, \& Bozeman, 2007). For example, Siegel, Waldman, and Link (2003) and Siegel, Waldman, Atwater, and Link (2004) conducted qualitative studies and concluded that faculty are not sufficiently rewarded for their involvement in university technology. Not surprisingly, then, there is little motivation for faculty to engage in such activities, which are clearly beneficial for universities. Similarly, if faculty reward systems are not modified to explicitly include scholarly impact outside the Academy, faculty will not be motivated to attempt to bridge the much-lamented science-practice gap.

Another implication of our results relates to the increasing pervasiveness of clinical professors or professors of practice in business schools in the United States. Faculty members in these positions are often expected to have a greater impact on outside stakeholders compared to those in more traditional professorial positions. Thus, our results point to new ways of gathering data regarding the relative performance of clinical professors and professors of practice.

Our results also have implications for the 
funding of business schools and universities in general. For example, the Higher Education Funding Council for England (2011), which provides funding to public universities, produced a document stating that "there will be an explicit element to assess the impact arising from excellent research, alongside the outputs and environmental elements." In other words, universities will have to provide evidence regarding impact on outside stakeholders. Our measure of impact based on number of Google pages represents an initial step in terms of the production of such documentation.

Finally, our measure of impact outside the Academy can be used in the future to gauge the progress of our field. AOM has put forth an ambitious strategic plan (Academy of Management Strategic Plan, 2012), and the AOM board is now focusing on engaging AOM leaders in a process of "strategic doing," which involves calls for proposals to achieve goals such as those related to professional impact, as mentioned earlier in our article. As an example, one of the specific objectives for the professional impact strategic intent is to "develop at least two new approaches to enhance our professional impact" (see http://strategicplan. aomonline.org/plan/objectives/by-strategic-intent). Our measure of impact outside the Academy can be used, over time, to gauge whether these and other initiatives are actually associated with an increase in our collective impact on external stakeholders.

\section{Concluding Comments}

Extant research assessing the impact of management scholars focuses almost exclusively on the impact on other academics (i.e., inside stakeholders) and consistently and uniformly uses total number of citations as the measure of impact. Our results indicate that impact inside the Academy cannot be equated with impact outside the Academy. Moreover, number of citations is unrelated to number of non-.edu Web pages (after controlling for number of years since receiving a doctorate and number of publications). Our results point to the need to investigate why some scholars and universities have more impact on outside stakeholders than others do. Also, given the need to narrow the science-practice gap, our results point to the possibility of creating a portfolio model of performance management systems in which the assessment and reward of performance is based on impact both inside and outside of the Academy. We hope our article will serve as a catalyst for future research and applications revisiting the concept and measurement of scholarly impact.

\section{Acknowledgments}

We thank Academy of Management Perspectives co-editor Donald S. Siegel and two anonymous reviewers for their encouragement and constructive feedback regarding our manuscript. Our work also benefited from comments offered by faculty and doctoral students from Cornell University (School of Hotel Administration and School of Industrial and Labor Relations). This study was supported in part by research project ECO2010-21078, financed by the Dirección General de Investigación of the Ministerio de Educación y Ciencia (Office for Research of the Spanish Ministry of Education and Science) and by FEDER funds.

\section{References}

Academy of Management Strategic Plan (2012). Explore the full plan. Retrieved from http://strategicplan. aomonline.org/plan/full

Adler, N. J., \& Harzing, A. (2009). When knowledge wins: Transcending the sense and nonsense of academic rankings. Academy of Management Learning and Education, 8, 72-95.

Aguinis, H. (2004). Regression analysis for categorical moderators. New York: Guilford.

Aguinis, H. (2013). Performance management (3rd ed.). Upper Saddle River, NJ: Pearson Prentice Hall.

Aguinis, H., Dalton, D. R., Bosco, F. A., Pierce, C. A., \& Dalton, C. M. (2011). Meta-analytic choices and judgment calls: Implications for theory building and testing, obtained effect sizes, and scholarly impact. Journal of Management, 37, 5-38.

Aguinis, H., \& Vaschetto, S. J. (2011). Editorial responsibility: Managing the publishing process to do good and do well. Management and Organization Review, 7, 407-422.

Aguinis, H., Werner, S., Abbott, J. L., Angert, C., Park, J. H., \& Kohlhausen, D. (2010). Customer-centric science: Reporting research results with rigor, relevance, and practical impact in mind. Organizational Research Methods, 13, 515-539.

Baldi, S. (1998). Normative versus social constructivist processes in the allocation of citations: A networkanalytic model. American Sociological Review, 63, 829846.

Barjak, F., Li, X., \& Thelwall, M. (2007). Which factors explain the web impact of scientists' personal home 
page? Journal of the American Society for Information Science and Technology, 59, 628-643.

Bansal, T., Bertels, S., Ewart, T., MacConnachie, P., \& O'Brien, J. (2012). Bridging the research-practice gap. Academy of Management Perspectives, 26(1), 73-92.

Bedeian, A. G. (2005). Crossing disciplinary boundaries: An epilegomenon for Lockett and McWilliams. Journal of Management Inquiry, 14, 151-155.

Blackburn, R. S., \& Mitchell, M. (1981). Citation analysis in the organizational sciences. Journal of Applied Psychology, 66, 337-342.

Cascio, W. F., \& Aguinis, H. (2008). Research in industrial and organizational psychology from 1963 to 2007: Changes, choices, and trends. Journal of Applied Psychology, 93, 1062-1081.

Cascio, W. F., \& Aguinis, H. (2011). Applied psychology in human resource management (7th ed.). Upper Saddle River, NJ: Pearson Prentice Hall.

Certo, S. T., Sirmon, D. G., \& Brymer, R. (2010). Competition and knowledge creation in management: Investigating changes in scholarship from 1988 to 2007. Academy of Management Learning and Education, 9, 591-606.

Chan, K. C., Fung, H., \& Leung, W. K. (2009). Influential research and institutions in international business research. Multinational Business Review, 17, 23-45.

Colquitt, J. A. (2011). From the editors: The next three years at AMJ-Maintaining the mission while expanding the journal. Academy of Management Journal, 54, 9-14.

Conway, J. M., \& Huffcutt, A. I. (2003). A review and evaluation of exploratory factor analysis practices in organizational research. Organizational Research Methods, 6, 147-168.

Cortina, J. M. (2011). Editorial. Organizational Research Methods, 14, 6-9.

Cronin, B., Snyder, H. W., Rosenbaum, H., Martinson, A., \& Callahan, E. (1998). Invoked on the Web. Journal of the American Society for Information Science, 49, 13191328.

Crossan, M. M., Maurer, C. C., \& White, R. E. (2011). Reflections on the 2009 AMR decade award: Do we have a theory of organizational learning? Academy of Management Review, 36, 446-460.

Endler, N. S., Rushton, J. P., \& Roediger, H. L. (1978). Productivity and scholarly impact. American Psychologist, 33, 1064-1082.

Freeman, R. E. (1984). Strategic management: A stakeholder approach. Boston: Pitman.

Furrer, O., Thomas, H., \& Goussevskaia, A. (2008). The structure and evolution of the strategic management field: A content analysis of 26 years of strategic management research. International Journal of Management Reviews, 10, 1-23.

Gomez-Mejia, L., \& Balkin, D. (1992). The determinants of faculty pay: An agency theory perspective. Academy of Management Journal, 35, 921-955.

Hambrick, D. C. (1994). 1993 presidential address: What if the Academy actually mattered? Academy of Management Review, 19, 11-16.
Harzing, A., \& van der Wal, R. A. (2009). Google Scholar h-index for journals: An alternative metric to measure journal impact in economics and business. Journal of the American Society for Information Science and Technology, 60, 41-46.

Hayton, J. C., Allen, D. G., \& Scarpello, V. (2004). Factor retention decisions in exploratory factor analysis: A tutorial on parallel analysis. Organizational Research Methods, 7, 191-205.

Higher Education Funding Council for England (HEFCE). (2011). Decisions on assessing research impact. Bristol: Higher Education Funding Council. Retrieved from http://www.hefce.ac.uk/research/ref/pubs/2011/01_11/

Hirsch, J. E. (2005). An index to quantify an individual's scientific research output. Proceedings of the National Academy of Sciences of the United States of America, 102, 16569-16572.

Ilgen, D. (2007). Citations to management articles: Cautions for the science about advice for the scientist. Academy of Management Journal, 50, 507-509.

Judge, T. A., Colbert, A., Cable, D. M., \& Rynes, S. L. (2007). What causes a management article to be citedArticle, author, or journal? Academy of Management Journal, 50, 491-506.

Kacmar, K. M., \& Whitfield, J. M. (2000). An additional rating method for journal articles in the field of management. Organizational Research Methods, 3, 392406.

Leung, K. (2007). The glory and tyranny of citation impact: An East Asian perspective. Academy of Management Journal, 50, 510-513.

Link, A. N., Siegel, D. S., \& Bozeman, B. (2007). An empirical analysis of the propensity of academics to engage in informal university technology transfer. Industrial and Corporate Change, 16, 641-655.

Lockett, A., \& McWilliams, A. (2005). The balance of trade between disciplines: Do we effectively manage knowledge? Journal of Management Inquiry, 14, 139150.

Molina-Azorin, J. F. (2012). Mixed methods research in strategic management: Impact and applications. Organizational Research Methods, 15, 33-56.

Morrison, A. J., \& Inkpen, A. C. (1991). An analysis of significant contributions to the international business literature. Journal of International Business, 22, 143154.

O'Boyle, E., \& Aguinis, H. (2012). The best and the rest: Revisiting the norm of normality of individual performance. Personnel Psychology, 65, 79-119.

Partington, D., \& Jenkins, M. (2007). Deconstructing scholarship: An analysis of research methods citations in the organizational sciences. Organizational Research Methods, 10, 399-416.

Pettigrew, A. M. (2011). Scholarship with impact. British Journal of Management, 22, 347-354.

Podsakoff, P. M., MacKenzie, S. B., Podsakoff, N. P., \& Bachrach, D. G. (2008). Scholarly influence in the field of management: A bibliometric analysis of the determinants of university and author impact in the manage- 
ment literature in the past quarter century. Journal of Management, 34, 641-720.

Rynes, S. L., Giluk, T. L., \& Brown, K. G. (2007). The very separate worlds of academic and practitioner periodicals in human resource management: Implications for evidence-based management. Academy of Management Journal, 50, 987-1008.

Shane, S. A. (1997). Who is publishing in the entrepreneurship research? Journal of Management, 23, 83-95.

Siegel, D. S., Waldman, D., Atwater, L. E., \& Link, A. (2004). Toward a model of the effective transfer of scientific knowledge from academicians to practitioners: Qualitative evidence from the commercialization of university technologies. Journal of Engineering and Technology Management, 21, 115-142.

Siegel, D. S., Waldman, D., \& Link, A. (2003). Assessing the impact of organizational practices on the relative productivity of university technology transfer offices: An exploratory study. Research Policy, 32, 27-48.

Simonton, D. K. (1997). Creative productivity: A predictive and explanatory model of career trajectories and landmarks. Psychological Review, 104, 66-89.

Thelwall, M., \& Sud, P. (2011). A comparison of methods for collecting web citation data for academic organizations. Journal of the American Society for Information Science and Technology, 62, 1488-1497.

van Fleet, D. D., McWilliams, A., \& Siegel, D. S. (2000). A theoretical and empirical analysis of journal rankings: The case of formal lists. Journal of Management, 26, 839-861.

Webmaster tools help—google.com. (February 15, 2012). Google search result count. Retrieved from http://www. google.com/support/webmasters/bin/answer.py?answer = 70920/ 